Copyright

By

Qian Wu

2013 
The Report Committee for Qian Wu

Certifies that this is the approved version of the following report:

Jobs-housing Balance: the Right Ratio for the Right Place

\section{APPROVED BY \\ SUPERVISING COMMITTEE:}

\section{Supervisors:}

Ming Zhang

Daniel Yang 


\title{
Jobs-Housing Balance: the Right Ratio for the Right Place
}

\author{
By Qian Wu, B.Arch.
}

\author{
Professional Report Proposal \\ Presented to the Faculty of the Graduate School of \\ The University of Texas at Austin \\ in Partial Fulfillment \\ of the Requirements \\ for the Degree of
}

Master of Science in Community and Regional Planning

The University of Texas at Austin

August 2013 


\section{Acknowledgements}

First and foremost, I want to thank the Ford Foundation and Institute of International Education (IIE). Their financial and spiritual support was indispensable. I want to thank my tutor in the Beijing office of IIE, Lili Jiang, who walked with me during my two-year journey in the United States. I want to thank two Ford fellows, Lun Dai and Yi-Fei Zhang. They, like my brothers, took care of me in the United States.

I want to thank my readers, Ming Zhang and Daniel Yang. I learned a great deal from their profound knowledge in land use and transportation planning. They provided great inspiration, detailed guidance, and support. I want to thank Ming-Chun Li. He is a very patient and warm-hearted tutor. He helped me progress in my studies.

I want to thank my friends, Allison Sherwin, Cynthia Umstattd, and Kristin Higgins. They, like angels, enriched my life in Austin.

Finally, I want to thank my selfless brothers and tolerant parents. They light up my life and encourage me to pursue my dreams. 


\begin{abstract}
Jobs-Housing Balance: the Right Ratio for the Right Place
\end{abstract}

\author{
Qian Wu, M.S.C.R.P \\ The University of Texas at Austin, 2013
}

Supervisor: Ming Zhang

CAMPO (Capital Area Metropolitan Planning Organization) is undergoing a revision of the regional transportation plan for Central Texas. The key goal of the plan is achieving sustainable development through integrating a multimodal transportation system with dense mixed land use. The CAMPO Plan has incorporated the growth management tool of jobs-housing balance to guide future land use development. To improve jobs-housing proximity and encourage compact growth, the concept of an activity center connected by high capacity transit corridors was employed in the plan, targeting the accommodation of 31 percent of the population and 38 percent of employment in Central Texas by 2035 (CAMPO 2035 Plan 2010). At the time when CAMPO was attempting to define appropriate ratios of jobs-housing balance for the activity centers, critical questions arose: what is a good ratio? Further, how should jobs-housing balance be quantified for guiding land use development? And to what extent could jobs-housing ratio be effectively used as an intervention instrument? 
This report attempts to provide theoretical and empirical evidence of jobs-housing balance and examine the applicability of jobs-housing balance ratio for different planning purpose in local context. Based on a rich literature review, the report removed the "deceptive simple concept" (Cervero 1991, p. 10) of jobs-housing balance on the surface and gathered insights on jobs-housing balance from existing exemplary studies. Absent a single consensus of a good jobs-housing balance ratio, the goal of this report is to present the possible ways of measuring and defining jobs-housing balance in complex urban development. This report analyzed existing jobs-housing balance of the Austin Region, presenting the truth of commute distance and jobs-housing balance ratio. Local municipalities might consider more factors in terms of the application of jobs-housing balance ratio in local context. 


\section{TABLE OF CONTENT}

ACKNOWLEDGEMENTS

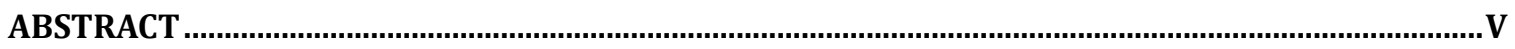

LIST OF FIGURES

LIST OF MAPS

1. INTRODUCTION

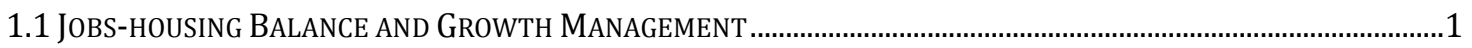

1.2 RESEARCH OBJECTIVES

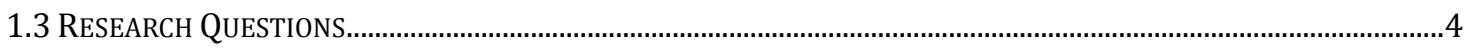

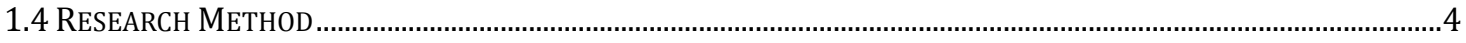

2. BACKGROUND

2.1 JoBS-HOUSING BALANCE AND GROWTH MANAGEMENT …...............................................................................

2.2 RAPID GROWTH OF AUSTIN ..........................................................................................................................6

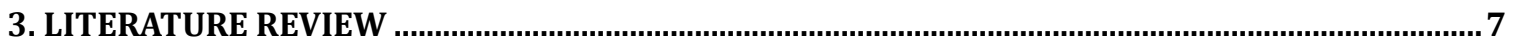

3.1 DEFINITION OF JOBS-HOUSING BALANCE..................................................................................................

3.2 SigNIFICANCE OF JOBS-HOUSING BALANCE ........................................................................................

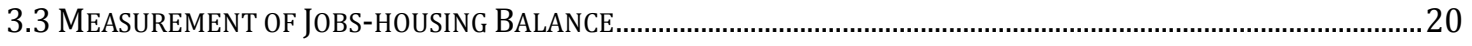

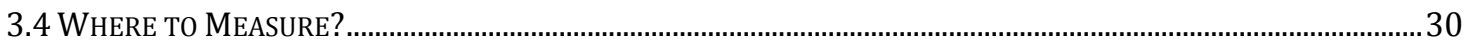

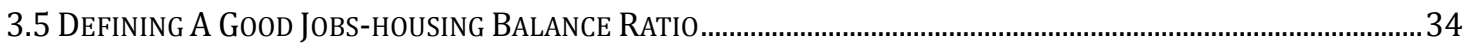

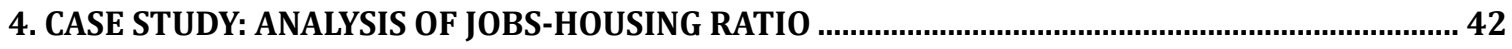

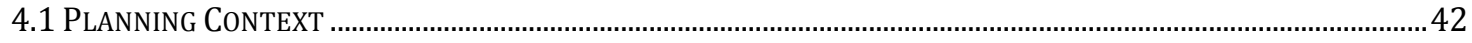

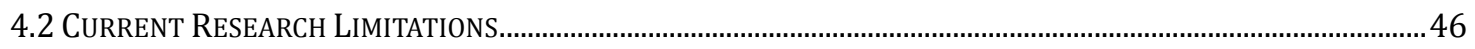

4.3 DEFINING STUDY AREA.......................................................................................................................... 47

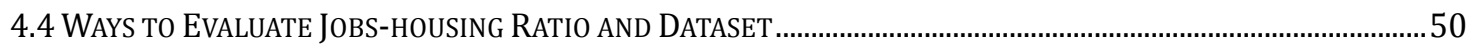

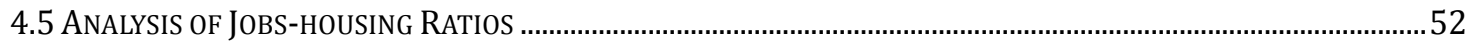

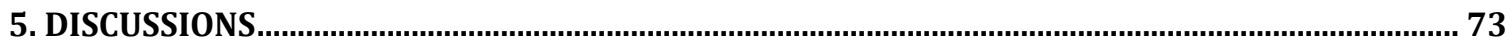

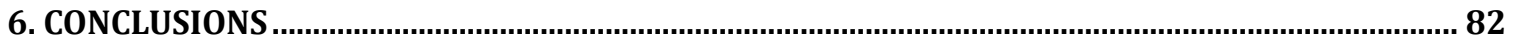

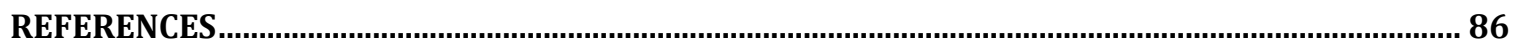




\section{LIST OF TABLES}

Table 1 Studies Quantifying Commuting Impact of Jobs-housing Balance.............. 16

Table 2 Interpretations of Variables of Jobs-housing Ratio .................................. 22

Table 3 Comparison of Three Measures of Jobs-housing Balance.......................... 27

Table 4 Recommended Jobs-housing Balance Ratios ........................................... 38

Table 5 Target Growth for Activity Centers ....................................................... 42

Table 6 Austin MSA Work to Home Travel Profile................................................. 52

Table 7 Changes in Jobs-housing Ratio and Commute Distance ........................... 53

Table 8 Region Profiles of Portland and Austin .................................................... 55

Table 9 Jobs-housing Ratios in Activity Centers (2005-2010)............................... 60

Table 10 Jobs-employed Resident Ratios and Travel Distance ............................... 64

Table 11 Target Jobs-employed Resident Ratios of Activity Centers ..................... 69 


\section{LIST OF FIGURES}

Figure 1 Estimated Jobs-housing Ratios ........................................................... 3

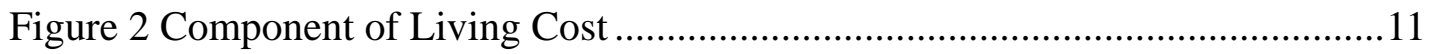

Figure 3 Activity Center Concept in Central Texas ............................................. 43

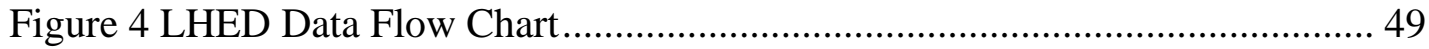

Figure 5 Job Distribution in CAMPO Region ................................................ 52

Figure 6 Jobs Counts by Distance/Direction in 2005 and 2010............................ 53

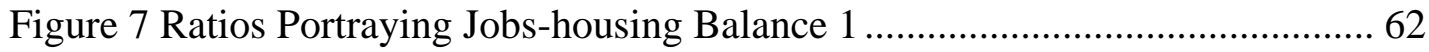

Figure 8 Ratios Portraying Jobs-housing Balance 2 ........................................ 62

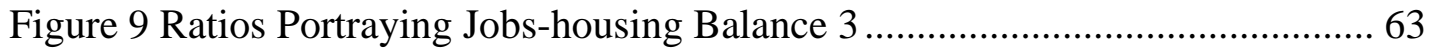




\section{LIST OF MAPS}

Map 1 Catchment Areas of Activity Centers ..................................................... 47

Map 2 Land Use Pattern in Central Austin ......................................................... 54

Map 3 Jobs-household Ratios of Activity Centers 2005 ....................................... 58

Map 4 Jobs-household Ratios of Activity Centers 2010 ..................................... 59 


\section{INTRODUCTION}

\subsection{Jobs-housing Balance and Growth Management}

Jobs-housing balance (JHB) has been highlighted since the 1970s and numerous studies have explored various ways to improve jobs-housing imbalance in North America. The Capital Area Metropolitan Planning Organization (CAMPO) has incorporated JHB into CAMPO 2035 Regional Transportation Plan (CAMPO 2010) through integrating 37 activity centers with multiple transportation modes. When CAMPO was undertaking drafting a new vision of the regional transportation plan for 2040, questions arose: How can JHB be implemented? How can JHB be captured through setting good jobs-housing ratios in the 38 activity centers (a new center will be added in 2040 plan)? What is the appropriate proportion of jobs and population for the activity centers? CAMPO has estimated a rough ratio of population and employment ranging from 1:4 to 4:1 depending on the roles of hierarchical activity centers in regional context (see figure 1). However, the suggested ratio is still debatable because of the lack of theoretical and empirical support. Determining appropriate target ratios for activity centers is appealing to CAMPO since increasing jobs-housing proximity is the essential goal of the regional transportation plan. A good ratio of jobs-housing will guide local municipalities to work toward jobs-housing balance by quantifying the ratio in various planning practices and 
implementation, such as comprehensive/master plan, neighborhood plan, and regulating plan.

What is a good ratio of jobs-housing balance? There is no universal answer in existing studies. Understanding the profound meanings of jobs-housing balance is crucial for CAMPO planners and decision makers to quantifying and qualifying jobs-housing balance in local settings. This report attempts to provide theoretical and empirical evidence of jobs-housing balance and examine the applicability of jobs-housing balance ratio for different planning purpose in local context. Based on a rich literature review, the report removed the "deceptive simple concept" (Cervero 1991, p. 10) of jobs-housing balance on the surface and gathered insights on jobs-housing balance from existing exemplary studies. Absent a single consensus of a good jobs-housing balance ratio, the goal of this report is to present the possible ways of measuring and defining jobs-housing balance in local dynamic urban development. 


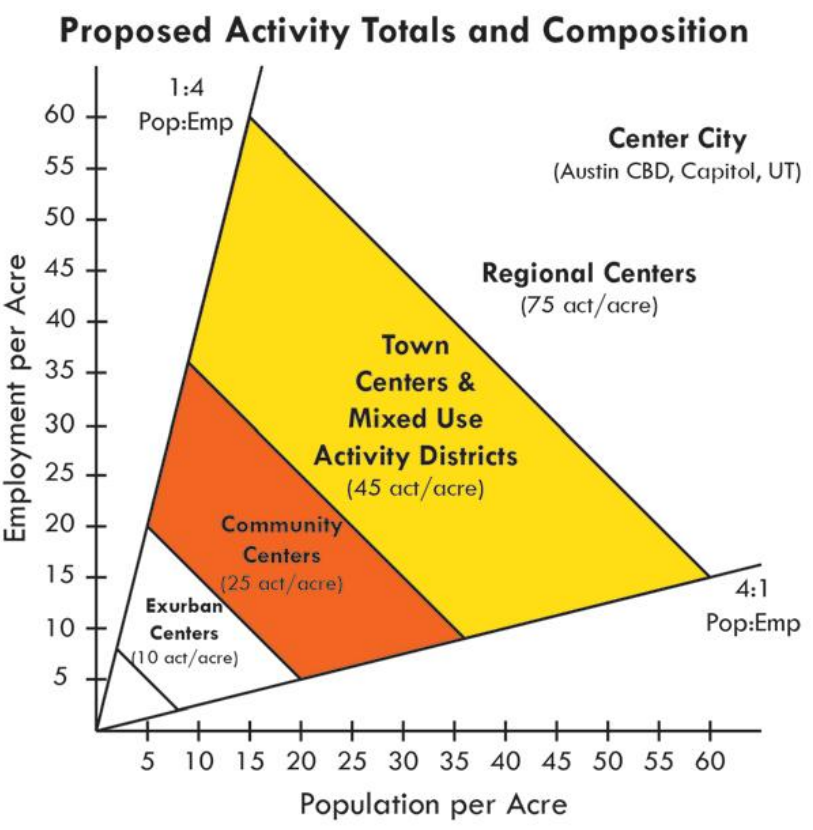

Figure 1 Estimated Jobs-housing Ratios (Source: Revised CAMPO Centers Criteria)

\subsection{Research Objectives}

The purpose of this study was to assemble insights into JHB for facilitating the designation of jobs-housing ratios in Central Texas. The research established three objectives:

a. Provide insights into jobs-housing balance through exemplary studies.

b. Gather the possible ways of measuring jobs-housing balance and examine the applicability of jobs-housing ratio.

c. Provide recommendations for promoting jobs-housing balance in Central

Texas. 


\subsection{Research Questions}

This research was built upon three questions:

a. How should jobs-housing balance be and appropriately and effectively applied in specific local settings?

b. What is hidden beyond the definition of jobs-housing balance?

c. What is the appropriate way of measuring jobs-housing ratio in local context?

\subsection{Research Method}

1. Literature Review. This paper will review the literature and identify multiple ways to measure jobs-housing balance and the feasibility of measures in Austin's setting.

2. Case Study. This paper will analyze the jobs-housing ratios for defined activity centers in Central Texas and examine the application of jobs-housing ratios.

3. Explore the appropriate geographic scale of catchment areas based on the literature review and urban development pattern in Austin.

\section{BACKGROUND}

\subsection{Jobs-housing Balance and Growth Management}

The ills of urban sprawl and suburbanization in the North America have been

criticized for many years. Traffic congestion, air pollution, long commutes, social 
problems as well as loss of farmland, fragile lands and open space have been attributed to the spatial separation of housing and work places (Loo \& Chow 2011, Zhao 2009). Many studies have revealed the inter-relationship between land use patterns and travel behavior. The spatial location of jobs and residence in regions has a strong impact on travel patterns (Cervero 1989, Ewing 1996, Zhao 2009, Loo \& Chow 2012), especially commute patterns (Bento et al. 2003, Cevero 1989, Downs 2004, Horner 2008, Horner \& Murray 2002, Gordon et al. 1991, Wang \& Chai 2009).

Jobs-housing balance has been highlighted as a policy tool and planning goal in improving job accessibility and housing affordability in many states in the U.S. For example, jobs-housing ratio has been adopted in Washington, California, and Georgia to guide future development. Jobs-housing ratio has been incorporated into either comprehensive land use plans or land use regulations (Miller 2010). Fairfax County, Washington D.C., has established goals of jobs-housing ratios for mixed land use centers to guide regional growth (Fairfax County Department of Planning \& Zoning Planning Division 2012). Similarly, the Sacramento region of California has set target jobs-housing ratios for regional activity centers and transportation corridors (SACOG 2012). Atlanta Regional Commission in Georgia has also applied jobs-housing ratio as a tool to examine zoning restrictions on affordable housing or small businesses (Miller 2010). 


\subsection{Rapid Growth of Austin}

Austin is one of America's top 12 fastest growing metropolitan areas (MSA) with the population increasing 11.6\% from 2007 to 2012 (Bloomberg 2013). Rapid growth, however, did not follow a sustainable and balanced pattern. Low-dense single-family development continues in suburban areas, associated with vehicle miles traveled (VMT) increase. Population decentralization and suburban expansion caused dramatically increasing transportation demand because of imbalance growth in the supply of jobs and housing. In the last decade, the trend of employment decentralization in central Texas and the mismatch of jobs and housing have caused a huge increase in long distance commuting along with traffic congestion in the main transportation corridor (CAMPO 2010). In 2013, Austin ranked the fourth most congested cities in the U.S. from 2012 to 2013 (http://scorecard.inrix.com/scorecard/). Along with transportation issues, air pollution and environmental deterioration have been highlighted in Central Texas. In addition, the expansion of urban land use in suburban areas has swallowed tremendous amounts of farmland and rangeland (CAMPO 2010, p.18-19).

Although in recent years, denser mix use, infill development and transit-oriented development have been encouraged in central Austin, jobs and housing imbalance is still a top issue due to most employment being centralized in Travis and Southern William Counties (Revised Draft CAMPO 2035 Regional Growth 
Concept 2007). With increasing transportation needs and infrastructure investment, the five counties in the Capital Area region, including Travis, Burnet, Williamson, Hays, Bastrop, and Caldwell, are confronting fiscal challenges. Central Texans are enduring the increase in transportation cost and its negative impact of the quality of life. Providing a more effective and efficient of land use and transportation system is the necessity of the capital management. Improving jobs-housing balance is a key task for Central Texas agencies and the Capital Metropolitan Planning Area Organization (CAMPO 2010).

\section{LITERATURE REVIEW}

\subsection{Definition of Jobs-housing Balance}

The concept of jobs-housing balance (JHB) stems from a balanced or self-contained community initiated by Howard, Purdom, and Munford (Giuliano 1991, p.305 \& 312). The term looks easily understandable but involves complex factors. Literally, it means that the number of jobs in a certain area is equal to the number of housing units in the same area. Some planning practices narrowly define JHB as a simple ratio. For instance, The Ontario Plan simply defines JHB as a ratio of 1.0 in terms of jobs to housing units and an imbalance if ratios are greater or lower than 1.0 (http://www.ontarioplan.org/index.cfm/31581). Miller interprets JHB as "equivalence in the number of an area's jobs and the area's residents seeking those jobs" (Miller 2011, p. 
iii).

Giuliano (1991) defines jobs-housing balance is "the distribution of employment relative to distribution of workers in a given geographic area” (p. 305). Real balanced communities should be "self-contained" or "self-reliant", which means employees have choice of available housing within a given area (Giuliano 1991). A true balance of jobs and housing is a spatial match of jobs and workers and residence. It implies the attainment of jobs within a reasonable commute distance to homes. The degree of balance is determined by the proportions of locally employed residents or locally reside workers in a defined area. Achieving true balance requires a" match-up" between jobs opportunities and workers' skills as well as housing price and worker's income" (Cervero 1989, p. 137).

Yang and Ferreira (2005) interpret jobs-housing balance as jobs-housing proximity, "the spatial relationship between workplace and residence". This definition not only covers the concept of JHB, but also embraces many terms related to the impact of urban development on commuting, such as accessibility, urban spatial structure, and spatial mismatch (Yang \& Ferreira 2005, p 172-172). By definition, balanced growth that requires qualitative and quantitative match between jobs and housing contributes to jobs-housing proximity and brings about commuting benefits. For example, spatial mismatch, as one form of jobs-housing imbalance, results in longer commuting distance as well as social problems (Horner \& Mefford 2007). Regarding spatial mismatch, 
Horner developed a measurement of JHB particularly for metropolitan areas with racial segregation. He suggested using a dissimilarity-based index or segregation indices to represent the degree of jobs-housing balance (Horner and Bernadette 2009).

How is JHB translated into real planning practice? The expression of JHB can be tracked to Margolis's discussion on the relationship between tax rate and land use pattern (residential and industry) in 1957. He primarily provided the concept of balanced community with a ratio of employment to resident labor force ranging from 0.75 to1.25. A city is seemed as a "dormitory city" if this ratio is lower than 0.75 and as an "industrial en-clave" if the ratio is larger than 1.25 (Margolis 1957, p. 227).

Cervero demonstrates that "jobs-housing ratio only indicates the potential for balance" (Cervero_1991, p12). Beyond the numerical balance, true JHB should be “self-containment". Evidence from Cervero's study (1996) in the San Francisco area shows that a small share of locally reside workers in some perfectly balanced cities, though jobs- employed residents ratios of twenty cities have been improved during the 1980s. Cervero concluded that there is a weak relationship between the ratio of JHB and self-containment. More complicated factors could affect JHB, such as unavailability of housing near workplaces. Giuliano also noted that real balance needs a "broad mix of housing type to accommodate households of a range of income categories" (Giuliano 1991, p 305). Nevertheless, jobs-housing ratio is the most popular and easiest way to measure jobs-housing balance because a quantified number is easy and feasible to be 
translated into land use planning and housing policy.

\subsection{Significance of Jobs-housing Balance}

\subsubsection{Benefits of Jobs-housing Balance}

Traffic congestion is the main factor that initiates concerns about jobs-housing balance (CRP 2008). A rich literature has proved that balanced growth in jobs and housing has a substantial impact on commuting and vehicle miles traveled (VMT) (Bento et al. 2003, Cervero 1989, Cervero \& Duncan 2006, Downs 2004, Ewing 1996, Frank \& Pivo 1994; Peng 1997, Weitz 2003). If the spatial distribution of jobs and housing can be balanced, tremendous vehicle travel will be reduced and traffic congestion will be relieved. For example, Cervero and Duncan's study found that increasing each $10 \%$ jobs within 4-mile radius of a dwelling place contributed to $2.99 \%$ reduction in VMT. If the job qualifications matched the worker's skills, the contribution was $3.29 \%$ (Cervero \& Duncan 2006). If housing is affordable near a workplace, most people are unwilling to drive long distances to work. In fact, one survey revealed that about $80 \%$ people indicate they want to live in neighborhoods that can reduce transportation cost (http://www.smartgrowthamerica.org/complete-streets/complete-streets-fundamentals/fact sheets/transportation-costs). According to 2001 National Household Travel Survey, home to work trips take up 27\% of total VMT in America (Miller 2010, p. iii).

Along with reduction in VMT and alleviation of traffic congestion, JHB offers 
benefits to travel cost, which is the second highest expenditure for most households after housing (http://htaindex.cnt.org/map/). A study by the Livability Initiative reveals potential saving at households' expense on transportation by improving jobs-housing location efficiency (see Figure 1).
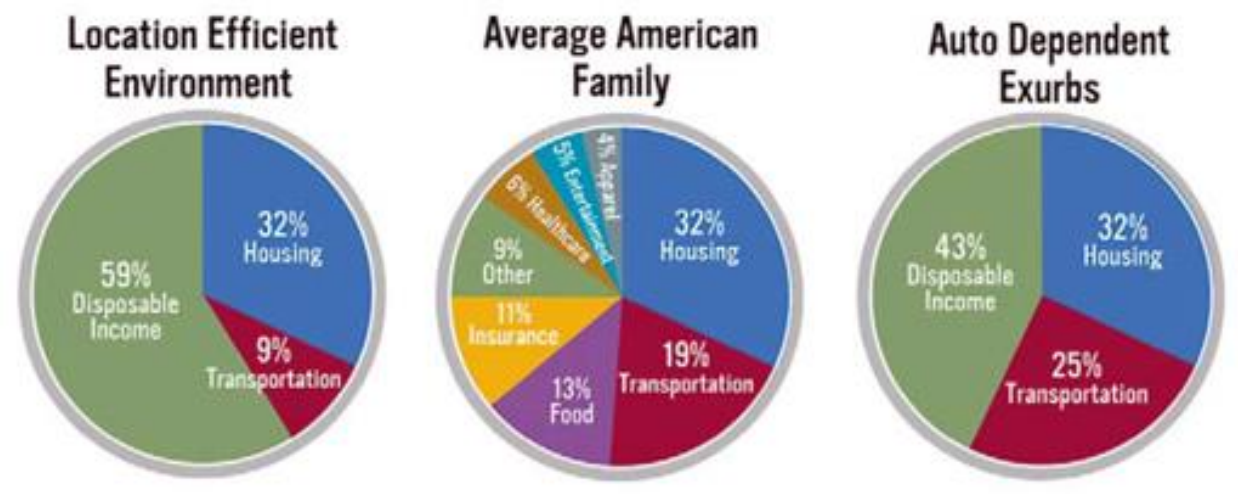

Figure3 Component of Living Cost

Source: Livability Initiative

http://www.fhwa.dot.gov/livability/fact sheets/transhouse attch1.cfm

In addition, by improving jobs-housing proximity, associated social and

environmental benefits could also be gained: better job accessibility, better air quality, lower public expenditure on infrastructures, greater family stability, more housing choices, more open space preservation and more travel choices (CPR 2008, p.5, Frank 1994, Giuliano 1991, Levine 1998, Macek \& Khattak 2001; Zhan, Shen \& Sussman 1999). Smart Growth Index 2.0 translates jobs-housing balance into an indicator, named as diversity, which link total vehicle trips and VMT with jobs-population ratio. Analyses on this indicator show that achieving jobs-housing balance can enhance economic and social vitality, expand housing choice, and encourage transit usage and non-motorized 
travel (CPR 2008, p. 6). Another marginal benefit of jobs-housing balance is improved personal health. A car-dependent lifestyle is seen as one reason for obesity, and many scholars have found that walking and biking are encouraged in mixed use communities with greater accessibility to destinations (Ewing \& Cervero 2001; Frank 1994; Handy, Cao \& Mokhtarian 2006).

Overall, there is a general consensus that improving JHB helps to alleviate traffic congestion and related problems, as well as social equity issues. However, findings from some scholars, Downs (2004), Giuliano (1991), Gordon (1991), and Levine (1998), do not approve of JHB as a means of reduction in traffic congestion (Miller 2010, p. v). The extent of commuting benefits of jobs-housing balance varies from region to region. The next section will discuss how JHB could affect commuting.

\subsubsection{Jobs-housing Balance and Commuting}

Extensive studies have found the relationship between land use pattern and travel behavior (Cervero1989, Ewing 1996, Loo \& Chow 2012, Zhao 2009). A number of studies have proved that there is clear correlation between spatial distribution of work place and residence and commuting distance or time (Bento et al. 2003, Cevero 1989, Cervero \& Duncan 2006, Frank 1994, Giuliano 1995, Levinson \& Kumar 1994, Peng 1997, Wang \& Chai 2009). Some studies conclude that jobs-housing balance or imbalance have a "modest impacts" on commuting pattern (Miller 2010, p. v). Bento et al. 
(2003) used an "imbalance indicator" referring to "the difference between the cumulative proportion of employment and the cumulative proportion of population" in a given area to detect the correlation between jobs-housing distribution and VMT (vehicle miles traveled) (p. 12-13). The result shows that a ten percent increase in indicator results in a 114 miles increase of VMT per household annually (Miller 2010, p. 15). Down's model in a hypothetical region shows that a maximum reduction of $9.5 \%$ in commute distance could be achieved by improving jobs-housing balance in exurb, suburb, and city center. Evidence in the Washington Puget Sound region also shows that the average commuting distance in the balanced census tracts (jobs-household ratio between 0.8 and 1.2) is reduced by $28 \%$ relative to defined unbalanced tracts (jobs-household ratio out the range of 0.8-1.2) (Miller 2010, p. 17). Cervero and Duncan's study in San Francisco Bay area reveals that 2.9 percent of VMT reduction can be gained from 10 percent of increase in job supply within a 4-mile residence area (Miller 2010, p. 17). Moreover, the researchers found that reduction in VMT could increase by 3.29 percent if job types fit the skills of resident workers (Cervero \& Duncan 2006). Wang and Chai's study in Beijing concludes that commuting time could significantly reduce by improving jobs-housing balance. Unlike earlier studies, jobs-housing balance in this study was directly calculated on individual's basis (individuals live and work in the same community and individuals live and work in different community) rather than aggregated census data (Miller 2010, p. 16-17). 
Conversely, a number of empirical studies show that relatively more balanced jobs-housing ratio has little impact on shorter commuting distance or time (Downs 1992, 2004; Miller \& Ibrahim 1998, Giuliano 1991, Giuliano \& Small 1993, Zehner 1977). Giuliano's study in the Los Angeles region found no obvious relationship between JHB and the mean distance of work trips. Evidence from the Los Angeles region illustrates that even suburban areas with poorer JHB than centers (at least 10,000 jobs and a density of at least 10 jobs per gross acre, core center is clustered centers around downtown Los Angeles), workers with jobs outside centers have a shorter work trip than those with jobs within centers. Giuliano indicates that other factors might benefit a shorter work trip in suburban areas, including negative externalities in centers (street connectivity, parking constrains, mobility); "homogeneity" of population characteristics in suburban areas; and the cluster of highly expertized jobs in city center but the preference of employees for low density environment in suburban areas (p. 308-309). Giuliano and Small's later study in Los Angeles region shows that average commuting time greatly increases when there is an extremely imbalanced jobs-housing ratio. The mean actual commuting time has a slightly negative correlation with workers/jobs ratios in individual job centers or sub-areas (Zhao 2009, p.70). Table 3 summarizes previous studies on JHB in relation to commuting.

Zhao (2009) concluded that the differences in the correlation between JHB and commuting result from four theoretical and methodological limitations (p. 71). First, the 
definition and measurement of JHB varies in different studies. Some studies calculate JHB by jobs/household (Levine 1998), others by jobs/housing units, jobs/ resident workers (Cervero 1989), and jobs/employed population (Giuliano1991, Cervero 1996). Frank considered the details of land use pattern in relation to commuting pattern, using land use mixture (residential and industrial land use) to measure jobs-housing balance. Some studies paid attention to socioeconomic factors, encompassing occupation (Zhou \&Wang 2012), work salary (Layman \& Horner 2010, Stoker \& Ewing 2012), housing price and affordability (Cervero 1989). Second, different studies applied different thresholds of jobs-housing ratios to detect changes in commuting patterns. For instance, Ewing used a jobs-household ratio between 1.3 and 1.7 as good range to capture internal work trips (Ewing 1996). Cervero suggests a jobs-household ratio of 1.5 as a ceiling value (Cevero 1989). The third limitation is variations in the geographic scales of study areas in previous studies. Some measurements follow jurisdiction boundary (Giuliano 1991) and sub-city level (Loo \& Chow 2011), some concentrate on census tracts (Frank \& Pivo 1994) or community districts (Zhao 2009), some use a circular range based on average minimum commute distance or actual average commute distance (Zhao 2009). Lastly, jobs-housing balance is more strongly affected by certain factors in different local settings, such as institutional influence (Zhao 2009), culture difference, demographic characteristics, work shifts rate, etc. Therefore, it is hard to quantify and qualify the impact of jobs-housing balance on commuting through merely examining spatial location of jobs and residence. 
Table 1 Studies Quantifying Commuting Impact of Jobs-housing Balance

\begin{tabular}{|c|c|c|c|c|c|}
\hline Study & Study Location & Geographic Unit & Measures & Result & Interpretation \\
\hline $\begin{array}{l}\text { Bento et al. } \\
\text { (2003) }\end{array}$ & $\begin{array}{l}1990 \text { National } \\
\text { Personal } \\
\text { Transportation } \\
\text { Survey }\end{array}$ & $\begin{array}{l}\text { City-wide, } \\
\text { households travel } \\
\text { survey }\end{array}$ & $\begin{array}{l}\text { Lorenz curve } \\
\text { (a plot of } \\
\text { cumulative } \\
\text { employment } \\
\text { against a plot } \\
\text { of cumulative } \\
\text { population) }\end{array}$ & JHB affects VMT & $\begin{array}{l}\text { Other factors have greater impact on } \\
\text { annual VMT such as } 10 \% \text { increase in } \\
\text { income ( }+568 \text { miles) or distance to } \\
\text { road transit stop (+167 miles). }\end{array}$ \\
\hline $\begin{array}{l}\text { Cervero } \\
(1996)\end{array}$ & $\begin{array}{l}\text { San Francisco Bay } \\
\text { Area }\end{array}$ & County & JER & $\begin{array}{l}\text { Jobs -housing imbalance } \\
\text { distinctly influences } \\
\text { commuting. }\end{array}$ & $\begin{array}{l}\text { Weak relationship between JER and } \\
\text { commute duration of employed } \\
\text { residents, but JER changes associates } \\
\text { with commute time of workers. }\end{array}$ \\
\hline & $\begin{array}{l}9 \text { pairs of planned } \\
\text { and unplanned U.S. } \\
\text { communities }\end{array}$ & Neighborhood & $\begin{array}{c}\text { Median } \\
\text { commute time }\end{array}$ & $\begin{array}{l}13.3 \% \text { reduction in travel } \\
\text { times for planned } \\
\text { communities. }\end{array}$ & $\begin{array}{l}\text { Modest commute changes can arise } \\
\text { from jobs/housing balance. }\end{array}$ \\
\hline $\begin{array}{l}\text { Cervero } \\
(1995)\end{array}$ & $\begin{array}{l}\text { New towns in } \\
\text { Britain, Paris, and } \\
\text { Stockholm }\end{array}$ & Neighborhood & JER & $\begin{array}{l}\text { Transit usage is improved } \\
\text { in balanced towns. }\end{array}$ & $\begin{array}{l}\text { More dramatic mode shifts arise } \\
\text { from availability of transport } \\
\text { infrastructure. }\end{array}$ \\
\hline $\begin{array}{l}\text { Cervero \& Duncan } \\
\qquad(2006)\end{array}$ & $\begin{array}{l}\text { San Francisco Bay } \\
\text { area, California }\end{array}$ & County & & $\begin{array}{l}\text { Changes in jobs/housing } \\
\text { balance have substantial } \\
\text { impact on VMT. }\end{array}$ & $\begin{array}{l}10 \% \text { increase in jobs within } 4 \\
\text { miles of residence reduces } \\
\text { VMT by } 2.99 \% \text { to } 3.29 \% \text {. }\end{array}$ \\
\hline $\begin{array}{l}\text { Downs } \\
(2004)\end{array}$ & $\begin{array}{l}\text { Hypothetical city with } \\
\text { imbalance and balance } \\
\text { ratios }\end{array}$ & Sub-city & JER & $\begin{array}{l}\text { VMT is decreased by } 9.5 \% \\
\text { in balanced city. }\end{array}$ & $\begin{array}{l}\text { Modest commuting impact can be } \\
\text { caused by great changes in } \\
\text { jobs-housing balance }\end{array}$ \\
\hline
\end{tabular}


Table 1 (continued)

\begin{tabular}{|c|c|c|c|c|c|}
\hline $\begin{array}{l}\text { Frank } \\
(1994)\end{array}$ & $\begin{array}{c}\text { Puget Sound, } \\
\text { Washington Region }\end{array}$ & Census tract & JER & $\begin{array}{l}\text { Better jobs-housing } \\
\text { balance contributes to } \\
\text { shorter trip distance and } \\
\text { time. }\end{array}$ & $\begin{array}{l}29 \% \text { reduction in commute distance } \\
\text { for trips ending in tracts with } \\
\text { balanced JER }(0.8-1.2) \text {. }\end{array}$ \\
\hline $\begin{array}{l}\text { Giuliano } \\
(1991)\end{array}$ & Los Angeles & County & JER & $\begin{array}{l}\text { JER has no impact on } \\
\text { commute distance. }\end{array}$ & $\begin{array}{l}\text { Factors besides jobs/housing balance } \\
\text { explain commute distance. }\end{array}$ \\
\hline $\begin{array}{l}\text { Horner \&Murray } \\
\qquad(2003)\end{array}$ & Atlanta region & Metropolitan region & MRC & $\begin{array}{l}\text { Jobs and housing } \\
\text { relocation significantly } \\
\text { change minimum } \\
\text { commuting. }\end{array}$ & $\begin{array}{l}82 \% \text { reduction in the minimum } \\
\text { commute time could be achieved } \\
\text { when only workers were relocated } \\
\text { whereas a smaller reduction of } 75 \% \\
\text { was achieved when only jobs were } \\
\text { relocated. }\end{array}$ \\
\hline $\begin{array}{l}\text { Horner } \\
(2008)\end{array}$ & Tallahassee, Florida & County & MRC & $\begin{array}{l}\text { Jobs and residential } \\
\text { relocation from } 1990 \text { to } \\
2000 \text { reduced minimum } \\
\text { commuting distance } \\
\text { slightly. }\end{array}$ & $\begin{array}{l}\text { When relocated workers in } \\
\text { downtown and jobs in suburban } \\
\text { locations than actual number. The } \\
\text { minimum commute length is reduced } \\
\text { by } 1.2 \text { mile. }\end{array}$ \\
\hline $\begin{array}{l}\text { Loo \&Chow } \\
\text { (2011) }\end{array}$ & Hong Kong (China) & $\begin{array}{l}\text { Sub-city (three } \\
\text { divided zones of } \\
\text { Hong Kong) }\end{array}$ & MRC & $\begin{array}{l}\text { Job relocation can save } \\
\text { commuting cost. }\end{array}$ & $\begin{array}{l}\text { Minimum commute time reduces in } \\
\text { polycentric urban structure with } \\
\text { balanced job and population. }\end{array}$ \\
\hline $\begin{array}{l}\text { Miller \& Ibrahim } \\
\text { (1998) }\end{array}$ & $\begin{array}{l}\text { Greater Toronto } \\
\text { (Canada) area }\end{array}$ & TAZ & $\begin{array}{l}\text { Job/Population } \\
\text { Ratio }\end{array}$ & $\begin{array}{l}\text { Ratio of jobs to people } \\
\text { shows little impact on } \\
\text { VMT }\end{array}$ & $\begin{array}{l}\text { Factors as population density, } \\
\text { employment density and distance to } \\
\text { CBD can better explain VMT. }\end{array}$ \\
\hline $\begin{array}{l}\text { Peng } \\
(1997)\end{array}$ & Portland, Oregon & Aggregated TAZs & JER & $\begin{array}{l}\text { Only extreme imbalanced } \\
\text { zones were observed great } \\
\text { change in commuting. }\end{array}$ & $\begin{array}{l}\text { When JHR is lower than } 1.2 \text { or } \\
\text { greater than } 2.8 \text {, VMT increase } \\
\text { significantly. }\end{array}$ \\
\hline
\end{tabular}


Table 1 (continued)

\begin{tabular}{|c|c|c|c|c|c|}
\hline $\begin{array}{l}\text { Wang and } \\
\text { Chai (2009) }\end{array}$ & Beijing (China) & $\begin{array}{l}\text { Sub-city } \\
\text { (aggregated } \\
\text { districts) }\end{array}$ & $\begin{array}{l}\text { Average } \\
\text { commute time }\end{array}$ & $\begin{array}{l}\text { People live and work in the } \\
\text { same neighborhood have } \\
\text { distinct shorter commute } \\
\text { duration than workers } \\
\text { residing outside. }\end{array}$ & $\begin{array}{l}\text { Residents working locally or } \\
\text { workers residing locally can use } \\
\text { non-motorized transportation with } \\
\text { shorter travel distance relative to } \\
\text { longer, congested commutes. }\end{array}$ \\
\hline $\begin{array}{l}\text { Yang \&Ferreira } \\
\quad(2005)\end{array}$ & $\begin{array}{l}\text { Boston and Atlanta in } \\
(1980-2000)\end{array}$ & Census tract & $\begin{array}{c}\text { JER, } \\
\text { MRC, AC, EC }\end{array}$ & $\begin{array}{l}\text { MRC seems the best } \\
\text { measure for commuting } \\
\text { impact of JHB }\end{array}$ & $\begin{array}{l}\text { MRC can be used across space, over } \\
\text { time and region-to- region. }\end{array}$ \\
\hline $\begin{array}{l}\text { Zehner } \\
(1977)\end{array}$ & $\begin{array}{l}13 \text { pairs of planned } \\
\text { and unplanned U.S. } \\
\text { communities }\end{array}$ & Neighborhood & $\begin{array}{l}\text { Median } \\
\text { commute time }\end{array}$ & $\begin{array}{l}\text { No variation in work trip } \\
\text { distance or time. }\end{array}$ & No impact on VMT. \\
\hline $\begin{array}{l}\text { Zhao } \\
(2009)\end{array}$ & Beijing (China) & Neighborhood & $\begin{array}{l}\text { Home based } \\
\text { job proximity } \\
\text { (HJP) }\end{array}$ & $\begin{array}{l}\text { HJP has a strong negative } \\
\text { impact on average } \\
\text { community commuting } \\
\text { time }\end{array}$ & $\begin{array}{l}68 \% \text { percent of changes in average } \\
\text { commuting time can be explained by } \\
\text { HJP. }\end{array}$ \\
\hline
\end{tabular}

Source: Adopted from Miller, John S. Feasibility of Using Jobs/Housing Balance in Virginia Statewide Planning, Virginia Transportation

Research Council (http://www.virginiadot.org/vtrc/main/online_reports/pdf/11-r1.pdf) 


\subsubsection{Barriers to Jobs-housing Balance}

Understanding the causes of jobs-housing imbalance helps planners and policy-makers to intervene with free market forces and close the gap of a jobs and housing mismatch. Cervero and Giuliano identified four socioeconomic forces that cause jobs-housing imbalance.

First, fiscal pressure and zoning restrictions result in the unbalanced distribution of employment and residence. Local governments favor revenue- generating development and exclude residential development through regulations, especially low-income housing (Giuliano 1991). There have been competitions between communities for attracting high-revenue generating industries, which have caused separation of housing and jobs (Cervero 1989). Developers are also interested in profitable investment because local fiscal policy usually requires developers to pay shared facility and capital cost in community.

Second, "growth moratoria" and growth ceilings on building permits have constrained housing supplies (Cervero 1989, p. 139). Low-income housing tends to be excluded by zoning regulations in many suburban municipalities because of high-cost and low-revenue. Low income housing is also resisted by existing residents due to the negative impact on the environment and the increased burden of facility (Giuliano 1991).

Third, a mismatch between workers' wages and housing prices has deepened the 
jobs-housing imbalance within a given area. Simultaneously, the mismatch has worsened class segregation. Moreover, demographic change causes difficulties in choosing residence location within an optimal commute distance. Households with multiple wage earners are more likely to choose housing located between the two workplaces in order to balance trip length (Cervero 1989, p. 139).

Fourthly, frequent job-switches cannot ensure home to work trips within a minimum distance year to year. Workers tend to prefer staying in their current house due to the higher cost of buying new houses than increased commuting cost (Cervero 1989, p. 139).

Finally, cultural characteristics and personal life style can also affect the spatial distribution of jobs and housing. For example, Texans are more likely to live in houses in low-dense communities supported by driving rather than denser mixed-use communities connected by transit, walking and biking. This is one reason that light-rail may not be accepted by Central Texans. Opposition to constructing affordable mixed-income housing might result from concerns about race and safety in communities with a long history of segregation (Turner, Popkin \& Lynette 2009).

\subsection{Measurement of Jobs-housing Balance}

How can JHB be quantified and qualified in the planning field? Well-respected studies have explored the correlation between the distribution of workers and residents 
and commute duration. In land use planning field, jobs-housing balance is evaluated by jobs-housing ratio, while many scholars from transportation field are more interested in quantifying jobs-housing balance by estimating theoretical commuting time and actual commuting time.

\subsubsection{Measuring by jobs-housing ratio}

Expressing jobs and housing balance by ratio has been widely accepted in planning practices. Yet scholars and researchers have different calculation of jobs-housing ratio. Some studies use jobs/housing units (Ewing 1996, Cervero1991, Weitz 2003), others use jobs/ households (CPR 2008); some studies use jobs/employed-residents (labor force) (Cervero 1989 \& 1996); and others use jobs/residents workers (Giuliano 1991). Giuliano (1991) also roughly calculated the ratio of jobs and population of Orange County as a way of evaluating longitude change in JHB. Some people argue that housing units include vacant housing units and might distort housing supply in communities. However, jobs-housing units is still a simple and adequate way to measure jobs-housing ratio if the average number of workforce per housing unit could be estimated (Weitz 2003, p. 4-5). Using jobs/housing units has merit in revealing the real supply of housing market if the ratio is used as an indicator of housing relocation. American Planning Association and CPR (2008) recommend the ratio of jobs-employed residents as the best expression because it's easier to evaluate the degree of balance if a ratio of 1.0 is signified as perfect balance (Weitz 2003, CPR 2008). 
In addition to disparity in denominator of the ratio, the variation in terms makes quantifying jobs-housing balance more complicated. For example, “jobs” may only include wage and salary workers (Giuliano 1991, p 305); it may also contain home-workers, or farmers (Miller 2010, p. 24). CPR (2008) also pointed out that incongruence of "jobs" counts could occur if data is provided by different entities. The three ways of measuring JHR_-jobs-housing units, jobs-household, and jobs-employed residents-- have confused planners and policy makers, let alone the non-specific term "workers" in the denominator side of "housing". The table below lists terms used in previous studies.

Table 2 Interpretations of Variables of Jobs-housing Ratio

\begin{tabular}{|c|c|}
\hline \multirow{2}{*}{ Weitz } & Jobs-Housing Ratio \\
\hline \multirow{3}{*}{ Cervero } & Employed residents= Labor force =Residents workers \\
\cline { 2 - 3 } & Wesidents workers = number of workers who reside locally \\
\cline { 2 - 2 } & Employed residents =Number of residents in the community who are employed \\
\hline \multirow{2}{*}{ Giuliano } & Resident workers =Labor force \\
\hline \multirow{2}{*}{ CPR } & Employed residents=those in the labor force who are currently working \\
\hline
\end{tabular}

The term "resident-workers" refers to different groups of population in the context of different studies. Labor force that includes unemployed residents cannot represent actual work trip demand in communities. Comparing the terms above, 
simplifying the term as jobs/employed residents (number of residents in the community who are employed) makes it easier for planners to review and assess JHB in different regions or cities. Jobs-housing ratios, to some extent, indicate the spatial distribution of workplace and residence. A numerical parity can poorly explain the degree of balance. As Cervero (1989) pointed out, real balance should rely on the percentage of residents who live and work locally. (p. 137) However, due to unavailable data and frequent job-shift in the U.S., few studies calculated jobs-housing ratio by the percentage of local-employed residents. Seeking a good jobs-housing ratio is still the goal of land use planners and policy makers since JHB has been widely used as a growth management tool. What is a good ratio? Empirical studies haven’t provided universal answers.

Considering the socioeconomic impact on jobs-housing proximity, more and more research measures JHB through classifying sampled groups by income, gender, working skill, and race (Stoker \& Ewing 2012, Layman \& Horner 2010, Cervero 1989). For example, housing price, occupation, skills of wage earners, and definition of measured tracts (residence or workplace) are considered in assessing jobs-housing proximity (Cervero 1989, Cervero \& Duncan 2006).

An alternative method to evaluating jobs-housing balance ratio was presented by Charron (2007), Horner and Marion (2008), using linear dissimilarity index and exponential dissimilarity index (Miller 2010, p. 27). For example, the linear dissimilarity index evaluates jobs-housing balance by measuring the proportion of jobs and workers 
within subunits relative to total regional jobs and workers. A value of equal to 1.0 means extreme imbalance; a value of 0 means perfectly balance. The equation is interpreted below:

$$
D=0.5 \sum_{i=1}^{n}\left|\frac{W i}{\text { Wtotal }}-\frac{H i}{\text { Htotal }}\right|
$$

$\mathrm{H}_{\mathrm{i}}$ the number of households, population, or employed residents in each subunit $\mathrm{W}_{\mathrm{i}:}$ the number of jobs in the same subunit

$\mathrm{H}_{\text {total }}$ : the number of households, population, or employed residents in the region $\mathrm{W}_{\text {total }}$ the number of jobs in the region (Miller 2010, p. 26).

Charron (2007) has noticed that a linear dissimilarity index might generate unreliable results. For example, if a jobs-rich unit is close to residence-rich units, the measured area might be evaluated as imbalance. Thus, the improved equation of exponential dissimilarity index was developed to measure jobs-housing balance ratio by considering the closeness of job-rich units and residence-rich units at metropolitan scales.

\subsubsection{Measures by Commuting}

Regarding the significant impact of jobs-housing balance on travel patterns, methodological tools for measuring JHB are promoted. Scholars and researchers have incorporated such variables as minimum (required) commuting (Buliung \& Kanaroglou 2002, Giuliano \& Small 1993, Hamilton 1982 \& 1989; Horner 2002, Loo \& Chow 2011, White 1988, Yang \& Ferreira 2005), excess commuting, (wasteful commuting)(Charron 
2007, Ma and Banister 2006a \&2006b, Yang 2008), maximum commuting (Black \&

Katakos, 1987, Horner 2002, Loo \& Chow 2011, Ma \& Banister, 2007), spatial mismatch

(Horner \& Mefford 2007, Immergluck 1998, Niedzielski 2006), and job or labor

accessibility (Shen 2000, Wang 2001, Levinson 1998, El-Geneidy \& Levinson 2006).

Some studies measure jobs-housing imbalance based on a study of the correlation

between minimum commuting or excess commuting and jobs-housing proximity. For

example, Loo and Chow (2011) employed minimum commuting and actual commuting

time to quantify the benefits of job relocation to residence.

Minimum (required) commuting is a theoretical time, assuming the most

efficient route between workplace and residence. It implies the potential for reduction in commuting distance. Maximum commute refers to a ceiling commute cost in "the theoretical worst-case scenario"(Loo \& Chow 2011,p556). Maximum commute is the theoretical capacity of commuting but this scenario would not happen because it is impossible that all the workers would choose the longest trip simultaneously. Minimum commute can better reflect the actual commute (Loo \& Chow 2011). Excess commuting, also known as wasteful commuting, refers to the space between minimum commute and the maximum commute. Excess commuting is the most debatable measurement. Ma and Banister (2007) claimed that excess commuting could explain nothing among different cities because of heterogeneity of residential and employments. Excess commuting indicates commute efficiency that could be improved by actual relative jobs-housing 
proximity rather than a "wasteful "commute that could be removed by jobs-housing balance. In reality, JHB cannot remove excess commute since traveler behavior is also influenced by socioeconomic characteristics (multi-workers, facilities, affordable housing around jobs center, etc.) (Loo \& Chow 2011)

\subsubsection{Comparison of Measurements}

There is a lack of widely acceptable standards of measuring JHB. The feasibility of these measurements depends on whether the impact of urban spatial pattern on commuting pattern exists and to what extent the impact is felt. Multiple methods were used to test correlation between jobs-housing proximity and commuting change, and to quantify the commuting impact of jobs-housing imbalance. Nevertheless, it is hard to compare these measurements since studies on commuting impact of JHB were conducted in different regions/cities at different geographic levels from different perspectives.

Yang and Ferreira, however, conducted a comparative evaluation of three categories of JHB measures, including jobs-employed resident ratio, accessibility, and minimum required commute (MRC). In order to make the results more comparable and reliable for the same regions, they used the dataset from Census Transportation Planning Packages (CTPP) 2000 consistent with the year 1980 and 1990 for the Boston and Atlanta metropolitan areas. The two regions are similar in population size but with different land use pattern. For the same jobs and housing distribution in a given area, three types of 
measurements resulted in different commuting impact on JHB. The table below summarizes the three measures used in Yang and Ferreira's research. 
Table 3 Comparison of Three Measures of Jobs-housing Balance (Yang \& Ferreira, 2005)

\begin{tabular}{|c|c|c|c|c|}
\hline \multicolumn{5}{|c|}{ Evaluation of Measures of Jobs-housing Proximity (from Yang \& Ferreira 2005) } \\
\hline Measures & $\begin{array}{l}\text { Suitability of } \\
\text { Geographic Scale }\end{array}$ & Equation & Pros & Cons \\
\hline JER & $\begin{array}{l}\text { Neighborhood } \\
\text { level }\end{array}$ & $\mathrm{JHR}=$ jobs/employed residents & $\begin{array}{l}\text {-Consistency with actual } \\
\text { commuting time in Atlanta and } \\
\text { Boston. } \\
\text {-Easiest way to measure. } \\
\text {-Clearly show job opportunities } \\
\text { and settlement. }\end{array}$ & $\begin{array}{l}\text {-Variation at different geographic scale. } \\
\text {-Change in JER cannot instantly reflect } \\
\text { jobs-housing proximity } \\
\text {-Weak in providing guidance for urban growth } \\
\text { strategies because it's hard to catch commuting } \\
\text { differences between regions when infill } \\
\text { development and densification reduce } \\
\text { commute distance. }\end{array}$ \\
\hline $\begin{array}{l}\text { Gravity type } \\
\text { Accessibility }\end{array}$ & $\begin{array}{l}\text { Neighborhood } \\
\text { level }\end{array}$ & $\begin{array}{c}D A A i=\sum_{j} \frac{O_{j} f(C i j)}{U A_{j}} \\
U A_{j}=\sum_{k} P_{k} f\left(C_{j k}\right) \\
f\left(C_{i j}\right)=\exp \left(-\beta * C_{i j}\right)\end{array}$ & $\begin{array}{l}\text {-Good for explaining urban form } \\
\text { and spatial structure in a large } \\
\text { region }\end{array}$ & $\begin{array}{l}\text {-Generate unusual positive relationship } \\
\text { between labor accessibility and workplace } \\
\text { commuting. } \\
\text {-Inconsistency between job DAA and labor } \\
\text { DAA because of "centrality advantage as } \\
\text { measurement noise". } \\
\text {-Periphery areas are mechanically assigned a } \\
\text { lower value of accessibility because of } \\
\text { remained strong boundary effect. } \\
\text {-Spatial decay function distorts real impact of } \\
\text { centrality on job DAA and labor DAA. }\end{array}$ \\
\hline
\end{tabular}


Table 3 (continued)

\begin{tabular}{|c|c|c|c|c|}
\hline MRC & $\begin{array}{l}\text { Polycentric urban } \\
\text { structure }\end{array}$ & $\begin{array}{l}\quad Z=\sum_{i} \sum_{j} C_{i j} X_{i j} \\
\sum_{j} X i j=N i \\
\sum_{i} X_{i j}=E_{j} \\
\quad \mathrm{X}_{\mathrm{ij} \geq 0} \\
\mathrm{Z}: \text { Total travel cost } \\
\quad \text { Ni and Ei: Total number } \\
\text { of workers and jobs } \\
\text { Xij: Number of workers living } \\
\text { in zone i and working in zone } \mathrm{j} \\
\text { Cij: Total travel cost } \\
\text { between zone i and } \mathrm{j} \text {. }\end{array}$ & $\begin{array}{l}\text {-Link urban development pattern } \\
\text { with commuting since it measures } \\
\text { jobs-housing proximity by } \\
\text { explicit commute cost } \\
\text {-Possible to aggregate data and } \\
\text { compare commuting change } \\
\text { between regions or year by year. } \\
\text {-More reliable because of } \\
\text { consistency with actual } \\
\text { commuting time. }\end{array}$ & $\begin{array}{l}\text {-Limitation in explain actual commute in low } \\
\text { density areas because the share of commuting } \\
\text { cost in real income decreases in decentralizing } \\
\text { regions. } \\
\text {-Constraints in the reallocation of jobs and } \\
\text { residential because the correlation between } \\
\text { MRC and AC is sensitive to local mobility } \\
\text { conditions. } \\
\text {-The magnitude of MRC affect jobs and } \\
\text { housing location choice significantly, thus } \\
\text { need additional evaluation of current } \\
\text { jobs-housing proximity for location } \\
\text { decisions. }\end{array}$ \\
\hline
\end{tabular}

JER: Jobs/employment ratio; DAA: Adjusted Accessibility; AC: Actual Commuting; MRC: Minimum Required Commuting 
Yang and Ferreira recommended that MRC is the best measure in terms of the correlation between commuting pattern and jobs-housing proximity. JER, nevertheless, is still valuable in directly grasping job opportunities and housing distribution. The selection of measure should consider the local settings: current characteristics of urban pattern, the trends of urban growth, the goals of future development, as well as the extent of the commuting impact of JHB or other urban problems. For example, Song found that actual commute distance could be better illustrated in polycentric cities rather than monocentric cities (Miller 2010, p. 64). As Yang and Ferreira (2005) pointed out, "Before we ask questions about whether job-housing proximity can explain commuting or to what extent commuting length relies on job-housing proximity, we should ask a more fundamental one: How can we characterize current urban development pattern in terms of a job-housing proximity?" (p. 171)

\subsection{Where to Measure?}

The primary question is to what extent jobs and housing could be balanced.

"The larger the size, the more likely the balanced-at the extreme, planet earth has a perfect balance of jobs and employed residents." (Cervero 1996, p. 495) Metropolitan areas should be balanced because it is defined by the aggregation of economically self-contained entities. But the spatial distribution of employment locations and different types of employment generate commuters within the region (Giuliano 1991, Peng 1997). 
"Overlapping commute sheds might exist because of dispersed distribution of employment characteristics of the U.S. metropolitan areas." (Giuliano 1991, p. 305) Jobs and housing are usually imbalanced at the blocks and census tract level. "There is no nonarbitrary geographic scale within which to assess the match or mismatch...[and] any desired outcome could be generated by simply adjusting catchment area boundaries"(Levine 1998, p. 134). Previous studies assess jobs-housing balance at different geographic levels based on data acquirement.

Some studies examine jobs-housing balance at the jurisdiction level. Giuliano (1991) examines the change in job-housing balance for Orange County in Los Angeles by calculating the ratio of employment to population from 1940 to 1985 . He also compares the change of JHB for each county in Los Angeles, from 1974 to 1988, by the ratio of resident workers/jobs. Cervero calculates jobs-housing ratio for larger cities in the San Francisco Bay Area (Cervero 1996). Similarly, Virginia Sate examines the change of JHB at county level. Jobs-housing ratios were calculated for counties of the Richmond Area, and the ratios were compared to average jobs-housing balance ratio in the region (Miller 2011).

Analysis on census tract level was conducted to detect the correlation between commuting and jobs-housing balance. Frank calculates jobs-household ratios by using census tract data and indicates a balanced ratio ranging from 0.8 to 1.2 (Frank 1994). Yang and Ferreira (2005) detected the correlation the impact of the ratio of job/employed 
residents, accessibility, and minimum commuting time at census tract level. Raja calculated Dallas' job-housing ratio by census tract (Raja 2012).

In fact, the micro level measurement is more likely to reflect relationship between travel behavior and land use pattern. At macro geographic level (county and city), large amounts of are internal work trips are neglected. Therefore, the majority of studies more favor disaggregate data at census tract basis. For instance, Zhao (2009) examines the commuting impact of JHB in eight districts of Beijing. Individual household data from sixty communities were used as basic survey unit to measure each community's jobs-housing balance. The findings show that job-housing proximity can contribute to about 70 percent of the changes in average commuting time.

However, Peng (1997) argues that census tract data cannot illustrate the reality of work-trip travel behavior. Because the size of census tract is based on population density rather than commuting shed, measuring jobs and housing balance within census tract or neighborhood is irrational since these methods tend to arbitrarily categorize work trips across neighboring census tracts or TAZs as jobs-housing mismatch. Thus, Peng suggests a "meso level" of geographic unit defined by average commuting time in the region. However, there is a lack of consensus as to the most appropriate size of circular area. Levingston recommended 6-8 miles as the home to work trip distance by driving, while Deakin thinks a work trip with 3-10 miles driving distance is acceptable (Peng 1997). Cervero uses 3-mile radius of suburban job centers to assess jobs-housing balance 
(Cervero 1989). Giuliano suggests using 3-mile circle rather than national estimate of 9-mile commute distance within suburban areas. Peng argues that a reasonable commuter shed should consider taking the average or median actual commute into account because actual average commute distance conveys information about the real impact of housing and employment locations on commuting. Thus, he recommended a 5-mile commuting distance as the radius of traffic analysis zone. The aggregated zones partially or totally covered by a 5-mile buffer should be the basic units of measurement (Peng 1997).

Another limitation of previous studies on jobs-housing balance is that there is no consensus on geographic scale of measuring JHB. Since JHB is utilized as either transportation policy or guidance for land use development, the factors that define the measuring scale should consider current urban spatial structure, growth policy, land capacity for development, administrative limitations of jurisdictions, the goal and the scope to measure JHB, as well as what kind of measures to be used. For example, if JHB policy aims to improve land use efficiency and mitigate congestion, if counties in the region have no power in zoning regulation, it is meaningless to measure JHB at the county level. Thus the measuring scale should target cities. In a spatial segregation city, if assessing JHB by commuting, the measurement of regional scale is worthless. Yang and Ferreira pointed out that JER and accessibility measures by using aggregated data of a region are unhelpful to explain commuting pattern (Yang and Ferreira 2005). Song also noticed that when using excess commuting for measuring JHB, lager zones in a certain 
region are less sensitive to excess commuting than smaller zones (Miller 2010, p. 63).

Overall, the ways to measure and the geographic scale of catchment area are the most important variables in assessing JHB. Selecting an appropriate measure at a feasible scale is specific for local municipalities. Without clear standards to follow, a good assessment of JHB comes from comprehensive understanding of the characteristics of urban structure and existing problems as well as specifying planning goals and demands of future development.

\subsection{Defining A Good Jobs-housing Balance Ratio}

What is a good jobs-housing ratio for a given area? There is no single criteria based on a review of the literature. The only consensus is that the appropriate ratio should be a range rather than an absolute and arbitrary number. The jobs-housing ratio only indicates the "potential for better balance". JHRs could vary from region to region and are a changing process from imbalance to balance, then back to imbalance (Cervero 1991, p. 12).

Disparities in ideal jobs-housing ratio result from differences in geographic scale and scope, ways of measurements, and specific local context. For example, the Southern California Council of Governments adopted the flexible range relative to regional average jobs-households ratio. Two variables were considered to evaluate the degree of jobs-housing balance. An acceptable commuting distance was estimated based on public 
survey. A regional average ratio was used as a benchmark to define targeted

jobs/households ratio within the acceptable commuting distance (14 miles). The closer to regional average ratio, the more balanced the community is (Miller 2010, p. 24). In the case of Florida, Ewing (1996) estimates appropriate jobs-housing balance ratio by capturing internal work trips within a defined area (usually 3-5 miles radius within a development site). He assumes that balanced communities could capture at least $30 \%$ internal work trips out of all work trips. He finds that of balanced communities with jobs to household ratio within 1.3 to 1.7 , more than one third of all work trips could be internal trips.

The equation is presented as:

Internal Capture $=0.35 \times$ Internal Jobs0 $.21 \times$ External Jobs- $0.19 \times$ Job Balance 0.28

Internal Jobs: the number of jobs within a locality.

External Jobs: the number of jobs outside the captured community.

Jobs Balance: the degree of local jobs to working residents. (Ewing 1996, p. 19-20)

Defining the goal of jobs-housing balance is not an easy task for planners and decision makers. Existing studies provide recommendations of good jobs-housing ratio in three measurements (see Table 4). Absent a consensus in recommended ratios, geographic scale does matter even when using the same measurement.

(1) Jobs to household ratio

Cervero defined 1.5 as threshold in a city, based on the assumption that 90 
percent of workers in the U.S. share housing with others and 70 percent of cohabitant households have two or more workers. As noted that in the literature review, his study focused on the San Francisco Bay Area with high economic connection and inter-work trips among cities, thus this assumption might not be suitable for low-urbanized cities, such as many cities in Central Texas. Ewing's estimate that is built upon internal work trips captured within a 3-5mile area is more rational.

Frank and Pivo's recommend balanced ratio by census tract is identified through relatively reduction of work trips distance along with changes in jobs-household ratios. Balanced census tracts are trip destinations with average work trips length (6.9 miles) $28 \%$ percent shorter that others (9.6 miles). Thus, the recommended ratio might fluctuate because of the change in travel distance, travel mode, and census tract size.

SACG (Southern California Association of Governments) established target jobs-household ratio within 14 miles of job centers through comparing with the regional average ratio of 1.25 . The recommended ratio was controlled within "the middle $20 \%$ of the SCAG region". As noted by SACG, this definition might be updated with variation in job center size, spatial distribution of job centers through the region. More importantly, the 14-mile commute shed was built upon acceptable travel time from public opinion. Then, acceptable travel time was translated into travel distance based on estimated average commute speed. Congestion and average commute time differ from region to region, and will change year to year. Moreover, the ratio from 1:1 to 1:1.29 based on one 
wage earner per household might be arbitrary (SACG 2001). An increase in wage earners per household is a demographic trend in most metropolitan areas in the U.S. Thus, it is necessary to estimate average wage earner per household when defining jobs-housing balance by jobs to household ratio.

Peng's study defines commute shed according to the mean commute distance of Portland metropolitan area. The catchment area is rational but cannot be universally applied to other metropolitan areas because of differences in travel pattern and the size of TAZ and metropolitan area. Portland is a medium-sized region. The spline function used in Peng's research might not fit to large metropolitan areas. The range of balanced ratio will possibly vary in localities due to differences in medium commute time and the radius of catchment areas.

\section{(2) Jobs to housing unit ratio}

Jobs-housing unit ratio seems to be deceptive because it usually conceals vacant housing units in communities. However, housing unit data at different geographic unit is easily obtained from census. Cervero's recommendation on jobs to housing unit ratio should be reconsidered according to local employment rate and housing occupancy rate since his assumption is that there are two or more workers per household. Sultana's definition of jobs-housing balance ratio relies on Cervero's study (1989) but the geographic level of his study is different from Cervero's. He defined jobs-housing

imbalance by aggregated TAZs instead of city level. Since larger areas are more likely to 
achieve numerical balance than small units, the ceiling ratio of 1.5 might be too general for 7-mile TAZs of the Atlanta Region. In Miller's Virginia metropolitan study, he noted that jobs-housing unit ratio explains lower degree of imbalance than jobs-employed resident ratio for the same community (Miller 2010, p. 25). Cervero also noticed that two medium-sized suburban communities in the San Francisco Bay Area had perfect jobs-housing units ratio, but with low percentage of residents who worked locally and workers residing locally (Cervero 1996).

(3) Jobs to employed resident ratio

The variable of employed residents is more than housing unit or household because household size varies in localities. Cervero's definition (1996) is reasonable because he considers the variations in land use patterns and travel patterns. He identifies the balanced ratio by adding a standard deviation of 0.5 based on the average jobs-employed resident ratio of the region.

In general, disparities in the definition of jobs-housing ratio do exist because of variations in measurements and measured units. However, it is clear that jobs-employed resident ratio is the most accurate way to quantify jobs-housing. Several studies have failed to explain changes in commute patterns based on the calculation of jobs-population ratio and jobs-housing units. Even the ratios had moved forward to balanced range, commute time or VMT increased (Cervero1989 \& 1996, Giuliano 1991, Miller 2010). In addition, no absolute jobs-housing balance ratio can be achieved since jobs-housing 
balance is a dynamic process. It is effective and reasonable to identify appropriate ratio range relative to regional average ratio. 
Table 4 Recommended Jobs-housing Balance Ratios

\begin{tabular}{|c|c|c|c|c|c|}
\hline Measurement & Study & Definition of JHB & Scale & Equation & $\begin{array}{c}\text { Recommended } \\
\text { Ratio }\end{array}$ \\
\hline $\begin{array}{l}\text { Jobs to household } \\
\text { ratio }\end{array}$ & \multirow[t]{2}{*}{$\begin{array}{l}\text { Cervero } \\
(1989)\end{array}$} & \multirow{2}{*}{$\begin{array}{l}\text { "the share of jobs in a community } \\
\text { actually filled by residents, and conversely } \\
\text { the share of } \\
\text { workers finding a place to live in that } \\
\text { community... a match-up between the skill } \\
\text { levels of local residents and job } \\
\text { opportunities as well as between the } \\
\text { earnings of workers and the cost of local } \\
\text { housing." }\end{array}$} & \multirow[t]{2}{*}{ City } & $\begin{array}{l}1.7 \text { jobs/cohabitant } \\
\text { household } * 0.9 \\
\text { cohabitant household }\end{array}$ & $\begin{array}{l}\text { Ceiling ratio } 1.5 \\
\text { (consider multiple } \\
\text { workers) }\end{array}$ \\
\hline $\begin{array}{l}\text { Degree of } \\
\text { self-containment }\end{array}$ & & & & $\begin{array}{l}\text { Workers residing } \\
\text { locally/workers }\end{array}$ & $1: 1$ \\
\hline \multirow{4}{*}{$\begin{array}{l}\text { Jobs to household } \\
\text { ratio }\end{array}$} & $\begin{array}{l}\text { Ewing } \\
(1996)\end{array}$ & Not mentioned & $\begin{array}{l}\text { 3-5 miles area around } \\
\text { a development site }\end{array}$ & & $1.3: 1$ to $1.7: 1$ \\
\hline & $\begin{array}{l}\text { Frank \& } \\
\text { Pivo } \\
(1994)\end{array}$ & $\begin{array}{l}\text { "Jobs-housing balance refers to the } \\
\text { distribution of employment in relation to the } \\
\text { distribution of households in an urban area." }\end{array}$ & Census Tracts & Jobs/households & $0.8: 1$ to $1.2: 1$ \\
\hline & $\begin{array}{l}\text { Peng } \\
(1997)\end{array}$ & $\begin{array}{l}\text { "Spatial relationship between the number of } \\
\text { jobs and housing units within a given } \\
\text { geographical area." }\end{array}$ & $\begin{array}{l}\text { TAZs totally and } \\
\text { partially covered by } \\
\text { 5-mile radius of a } \\
\text { central TAZ }\end{array}$ & Jobs/households & $1.2: 1$ to $2.8: 1$ \\
\hline & $\begin{array}{l}\text { SCAG } \\
(2001)\end{array}$ & $\begin{array}{l}\text { "A provision of an adequate supply of } \\
\text { housing to house workers employed in a } \\
\text { defined area (i.e., community or } \\
\text { sub-region)" }\end{array}$ & $\begin{array}{l}\text { Commute shed } \\
\text { within } 14 \text { miles } \\
\text { radius of job centers }\end{array}$ & Jobs/households & $1: 1$ to $1: 1.29$ \\
\hline
\end{tabular}


Table 4 (continued)

\begin{tabular}{|c|c|c|c|c|c|}
\hline $\begin{array}{l}\text { Jobs to population } \\
\text { ratio }\end{array}$ & \multirow{2}{*}{$\begin{array}{c}\text { Giuliano } \\
(1991)\end{array}$} & \multirow{2}{*}{$\begin{array}{l}\text { "Jobs-housing balance refers to } \\
\text { the distribution of employment } \\
\text { relative to the distribution of } \\
\text { workers within a given } \\
\text { geographic area." }\end{array}$} & County & Jobs/population & \multirow{2}{*}{$\begin{array}{l}\text { Acceptable range of } \\
\text { balanced ratio relative } \\
\text { to regional average } \\
\text { ratio. }\end{array}$} \\
\hline $\begin{array}{l}\text { Resident-workers } \\
\text { to jobs ratio }\end{array}$ & & & County & $\begin{array}{l}\text { Residents } \\
\text { workers/jobs }\end{array}$ & \\
\hline \multirow{2}{*}{$\begin{array}{l}\text { Jobs to housing } \\
\text { unit ratio }\end{array}$} & $\begin{array}{l}\text { Cervero } \\
(1991)\end{array}$ & $\begin{array}{l}\text { It refers to worker have } \\
\text { opportunities to live within a } \\
\text { reasonable distance to } \\
\text { workplace. }\end{array}$ & $\begin{array}{l}\text { Medium-sized suburb } \\
\text { community or sub-region }\end{array}$ & $\begin{array}{l}\text { Jobs/housing } \\
\text { units }\end{array}$ & $\begin{array}{l}1.4: 1 \text { to } 1.6: 1 \text { (multiple } \\
\text { workers/housing unit) }\end{array}$ \\
\hline & Sultana & $\begin{array}{l}\text { "A community is considered } \\
\text { balanced when residential and } \\
\text { employment distributions are } \\
\text { approximately equal." }\end{array}$ & $\begin{array}{l}\text { TAZs within } 7 \text { miles radius of } \\
\text { the zone centroid }\end{array}$ & $\begin{array}{l}\text { Jobs/housing } \\
\text { units }\end{array}$ & $0.75: 1$ to $1.5: 1$ \\
\hline \multirow[b]{2}{*}{$\begin{array}{l}\text { Jobs to employed } \\
\text { resident ratio }\end{array}$} & $\begin{array}{l}\text { Cervero } \\
(1996)\end{array}$ & Not mentioned & City & $\begin{array}{l}\text { Jobs/employed } \\
\text { residents }\end{array}$ & $0.8: 1$ to $1.25: 1$ \\
\hline & $\begin{array}{c}\text { Yang \& } \\
\text { Ferreira } \\
(2005)\end{array}$ & $\begin{array}{l}\text { "The spatial proximity between } \\
\text { workplace and residence", and } \\
\text { qualitative and quantitative } \\
\text { match between jobs and } \\
\text { housing. }\end{array}$ & $\begin{array}{l}\text { Floating areas involve } 10 \\
\text { closest census tracts. Or census } \\
\text { tracts "whose centroid are } \\
\text { within } 10 \text { miles radius of target } \\
\text { census tract." }\end{array}$ & $\begin{array}{l}\text { Jobs/employed } \\
\text { residents }\end{array}$ & NA \\
\hline
\end{tabular}




\section{CASE STUDY: ANALYSIS OF JOBS-HOUSING RATIO}

\subsection{Planning Context}

\subsubsection{CAMPO 2035 Regional Transportation Plan}

CAMPO is responsible for developing and updating the Regional Transportation Plan for the Capital Area every five years. Facing the dilemma of increasing transportation needs and funding constraints for infrastructure, the CAMPO 2035 Plan developed a comprehensive multi-model transportation system that integrates with sustainable land use development. The concept of activity centers is the key strategy to improve the jobs-housing balance and alleviate traffic congestion and VMT. Guided by the concept, funds for the next 25 years will focus on improving public transit availability and accessibility. Activity centers will accommodate new growth with higher density and mixed-use development supported by a more efficient multiple mode transportation system, including walking, biking, light-rail, bus, and moderate driving. The CAMPO 2035 Plan assumes that $31 \%$ and $38 \%$ of the total population and employment respectively in CAMPO region would be allocated in 37 activity centers by 2035 (CAMPO 2010, p. 22). The targeted growth for each center aims to achieve a balance growth in housing and jobs locally (see Table 5 and Figure 4).

The strategy of activity centers will shape a sustainable Central Texas through 
controlling urban sprawl and balancing growth in suburban area. Higher density and mixed development around main transit corridors and stations will contribute to jobs-housing proximity with associated benefits, such as the mitigation of traffic congestion in central Texas. Activity centers are categorized as large, medium, or small centers. The conceptual locations and growth targets of these centers are the results of long-term conversations between CAMPO members and regional experts during 2006 and 2007 (CAMPO 2010, p. 19). The growth target has been adopted and will guide future land use development and transportation investment in the Capital Region. In 2013, under the requirement of updating Regional Transportation Plan for 2040, CAMPO is considering drafting more rational growth targets for 38 activity centers. Growth targets indicate the redistribution of population and employment in 25 years. However, there is a heated debate about what appropriate ratio of population to employment is for each center. CAMPO's new version of Regional Transportation Plan suggests 4:1 as an appropriate ratio of jobs to population for all activity centers. Nevertheless, because of limited empirical or theoretical evidence, this index may not be widely accepted by planners, developers, decision makers, and communities. Many states have adopted jobs-housing balance ratio as guidance for land use development (Miller 2010). However, there is limited research on activity centers. Also, no research has defined an optimal ratio or a ceiling index. Defining appropriate jobs-housing ratio is CAMPO's desire for future guidance on the regional distribution of housing and jobs, which will essentially affect proportionally funding investment. Additionally, it is meaningful for researchers to 
explore and assess the jobs-housing balance under this particular setting.

Table 5 Target Growth for Activity Centers

\begin{tabular}{|c|c|c|c|c|c|c|c|}
\hline \multirow[t]{3}{*}{2035 Activity Center } & \multirow[t]{3}{*}{ Jurisdiction } & \multicolumn{4}{|c|}{ Existing $(2005)^{1}$} & \multirow{3}{*}{$\begin{array}{l}\text { Center } \\
\text { Type }^{2}\end{array}$} & \multirow[t]{3}{*}{ Future (2035)Targets ${ }^{3}$} \\
\hline & & \multicolumn{2}{|c|}{ Jobs } & \multicolumn{2}{|c|}{ Population } & & \\
\hline & & Total & $\begin{array}{l}\% \text { of } \\
\text { region }\end{array}$ & Total & $\begin{array}{l}\% \text { of } \\
\text { region }\end{array}$ & & \\
\hline Central Austin & Austin & 150,000 & $21.5 \%$ & 65,000 & $4.5 \%$ & Large & $\begin{array}{l}125,000-500,000 \text { people } \\
\text { and } \\
200,000-300,000 \text { jobs }\end{array}$ \\
\hline Bastrop & Bastrop & 5,000 & $0.7 \%$ & 3,000 & $0.2 \%$ & \multirow{12}{*}{ Medium } & \multirow{12}{*}{$\begin{array}{l}\text { Within each medium } \\
\text { center: } \\
9,000-75,000 \text { people } \\
\text { and } \\
9,000-40,000 \text { jobs }\end{array}$} \\
\hline Elgin & Elgin & 3,000 & $0.4 \%$ & 5,000 & $0.3 \%$ & & \\
\hline Georgetown & Georgetown & 2,000 & $0.3 \%$ & 4,000 & $0.3 \%$ & & \\
\hline Howard Lane & Austin & 3,000 & $0.4 \%$ & 2,000 & $0.1 \%$ & & \\
\hline Hutto & Hutto & 1,000 & $0.1 \%$ & 1,000 & $0.1 \%$ & & \\
\hline Kyle & Kyle & 1,000 & $0.1 \%$ & 6,000 & $0.4 \%$ & & \\
\hline Leander & Leander & 1,000 & $0.1 \%$ & 4,000 & $0.3 \%$ & & \\
\hline Lockhart & Lockhart & 2,000 & $0.3 \%$ & 7,000 & $0.5 \%$ & & \\
\hline North Burnet Gateway & Austin & 26,000 & $3.7 \%$ & 4,000 & $0.3 \%$ & & \\
\hline Pflugerville & Pflugerville & 1,000 & $0.1 \%$ & 8,000 & $0.5 \%$ & & \\
\hline Round Rock & Round Rock & 8,000 & $1.1 \%$ & 8,000 & $0.5 \%$ & & \\
\hline San Marcos & San Marcos & 12,000 & $1.7 \%$ & 14,000 & $1.0 \%$ & & \\
\hline Bee Cave & Bee Cave & $<500$ & $<0.1 \%$ & $<500$ & $<0.1 \%$ & \multirow{24}{*}{ Small } & \multirow{24}{*}{$\begin{array}{l}\text { Within each small activity } \\
\text { center: } \\
2,000-10,000 \text { people } \\
\text { and } \\
2,000-10,000 \text { jobs }\end{array}$} \\
\hline Ben White & Austin & 2,000 & $0.3 \%$ & 2,000 & $0.1 \%$ & & \\
\hline Buda & Buda & 1,000 & $0.1 \%$ & 1,000 & $0.1 \%$ & & \\
\hline Cedar Park & Cedar Park & 1,000 & $0.1 \%$ & 1,000 & $0.1 \%$ & & \\
\hline Decker & Austin/Travis Co & $<500$ & $<0.1 \%$ & $<500$ & $<0.1 \%$ & & \\
\hline Del Valle & Austin & $<500$ & $<0.1 \%$ & $<500$ & $<0.1 \%$ & & \\
\hline Dripping Springs & Dripping Springs & $<500$ & $<0.1 \%$ & $<500$ & $<0.1 \%$ & & \\
\hline Highland Mall & Austin & 6,000 & $0.9 \%$ & 3,000 & $0.2 \%$ & & \\
\hline \begin{tabular}{|l|l} 
Jarrell \\
\end{tabular} & Jarrell & $<500$ & $<0.1 \%$ & $<500$ & $<0.1 \%$ & & \\
\hline Liberty Hill & Liberty Hill & $<500$ & $<0.1 \%$ & $<500$ & $<0.1 \%$ & & \\
\hline Luling & Luling & $<500$ & $<0.1 \%$ & 2,000 & $0.1 \%$ & & \\
\hline Manor & Manor & 1,000 & $0.1 \%$ & 1,000 & $0.1 \%$ & & \\
\hline Mueller & Austin & 1,000 & $0.1 \%$ & 1,000 & $0.1 \%$ & & \\
\hline Mustang Ridge & Mustang Ridge & $<500$ & $<0.1 \%$ & $<500$ & $<0.1 \%$ & & \\
\hline Northwest & Austin & 1,000 & $0.1 \%$ & $<500$ & $<0.1 \%$ & & \\
\hline Oak Hill & Austin & 1,000 & $0.1 \%$ & 2,000 & $0.1 \%$ & & \\
\hline Smithville & Smithville & $<500$ & $<0.1 \%$ & 1,000 & $0.1 \%$ & & \\
\hline South Austin Station & Austin & $<500$ & $<0.1 \%$ & 4,000 & $0.3 \%$ & & \\
\hline Taylor & Taylor & 1,000 & $0.1 \%$ & 2,000 & $0.1 \%$ & & \\
\hline Tech Ridge & Austin & 2,000 & $0.3 \%$ & 2,000 & $0.1 \%$ & & \\
\hline University Blvd & Round Rock & $<500$ & $<0.1 \%$ & $<500$ & $<0.1 \%$ & & \\
\hline IH-35 \& SH 45 N & Round Rock & 6,000 & $0.9 \%$ & 1,000 & $0.1 \%$ & & \\
\hline SH 130 \& US 290 & Austin & $<500$ & $<0.1 \%$ & $<500$ & $<0.1 \%$ & & \\
\hline RM 2222 \& RM 620 & Austin & 1,000 & $0.1 \%$ & $<500$ & $<0.1 \%$ & & \\
\hline $\begin{array}{l}\text { All Activity Centers } \\
\text { (Total) }\end{array}$ & & 239,000 & $34.2 \%$ & 159,000 & $10.9 \%$ & & $\mathbf{2 1 . 5} \%$ of regional population \\
\hline & & & & & & & $36.4 \%$ of regional jobs \\
\hline
\end{tabular}




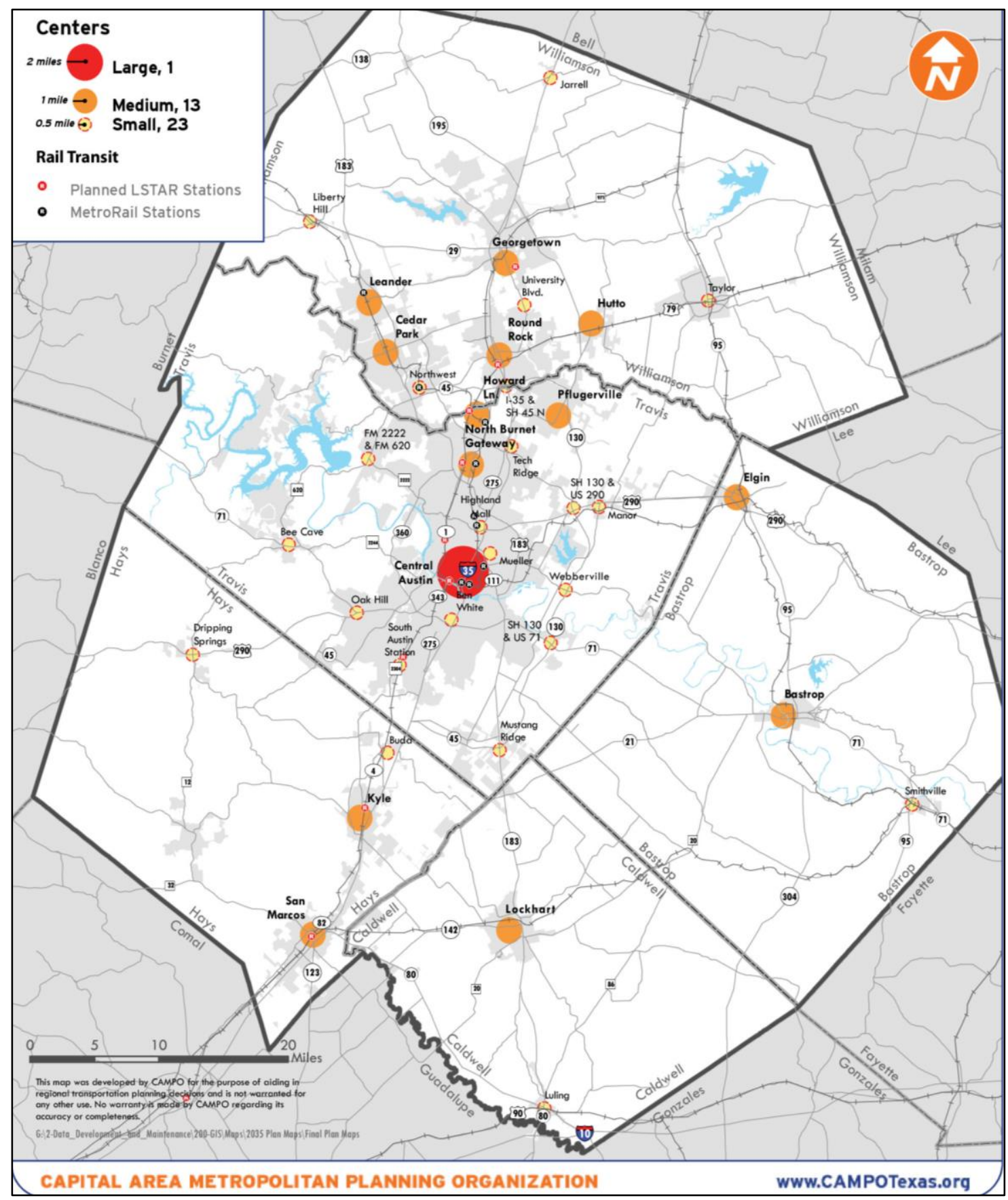

Figure 4 Activity Center Concept in Central Texas

(Source: CAMPO 2035 Plan downloaded from CAMPO website:

http://www.campotexas.org/programs_plan.php) 


\subsection{Current Research Limitations}

Many regions in the U.S. have integrated the concept of activity centers in land use plans with regional transportation plans, such as Sacramento, Salt Lake City, and counties in Washington metropolitan area (such as Fairfax, Puget Sound). These cities have adopted a JHB policy to guide land development within activity centers. The indicator of jobs-housing ratio is the main measures of JHB in these cities' land use plan. However, these practices haven't provided theoretical evidence or systematic analysis in terms of the catchment area of JHB and targeted ratios of jobs-housing balance. For example, the regional transportation plan of the Sacramento Area measures JHB within four miles of regional job centers. The definition of catchment area is general and lacking of specific consideration on the characteristics of activity centers.

Although CAMPO 2035 Plan has provided assessment of JHB for activity centers, there are still limitations:

-The catchment area of JHB is based on the conceptual boundary of activity centers. There is a lack of consideration of the characteristics of activity centers in the Austin Region in terms of location, function, transit service, current land use pattern, and size at city and regional level. For example, some small centers with rail stop and bus stops might measure jobs-housing ratios on a larger scale than those without transit availability, such as the Northwest center. Some small centers might have no land capacity for targeted population and jobs within 0.5 mile radius are, such as Highland 
Mall.

- The measure of jobs-housing ratio is too rough by calculating the ratio of employment to population. This method conceals the unemployed group in communities and thus cannot directly reveal jobs distribution and housing demands in given areas. In addition, because of variation in household size, it is not appropriate to evaluate JHB by jobs-population ratio if one job per labor force is signified as a baseline in a self-contained community.

\subsection{Defining Study Area}

A significant part of the existing debate about the jobs to employed-residents ratio is the definition of the geographic scale of catchment area. Some studies found a weak relationship between commuting distance and jobs-employed resident at the jurisdiction level (Giuliano 1991, Peng 1997). Empirical studies found that commuting duration changes greatly at the neighborhood level (See Table 3). As stated above, the catchment areas of measuring JHB varies in region, depending on the characteristics of study area, existing conditions, as well as the goals and the demands of future development.

Activity centers defined in the CAMPO 2035 Plan are designated for improving land use efficiency, increasing transit ridership, and reducing VMT. Thus, the assessment of JHB for activity centers should analyze the roles of these centers in relation to current 
and future function in regional transportation network and the potential needs and the capacity of activity. The CAMPO 2035 Plan roughly categorizes 37 centers as large, medium, and small centers, with activity circle of 2 miles, 1 mile, and 0.5 mile radius respectively. The center size was defined based on the evaluation of strength of centers. The conceptual boundaries of the activity centers are vague to extract data for measuring existing jobs-housing balance. Some current boundaries of activity centers fail to catch important land use features. For example, Highland Mall did not include mixed land use in the north of the site, which would completely change the jobs-housing balance ratio.

Drawing from methods from precious studies (Peng 1997, Sultana 2002, SCAG 2001), it is rational to define measuring units by commute shed. According to a 2004 Austin Commuter Survey report, home-to-work trip distance ranges from a quarter mile to 70 miles. The average commute distance is 12.3 miles in the Austin area. 72 percent of workers commute within 15 miles to workplace, and only 28 percent of workers travel more than 15 miles (Bhat et.al. 2004, p. 41). If the study uses average commute distance as commute shed of jobs-housing balance analyses, all the activity centers will join together since there are many activity centers designated close to each other. Therefore, this study redefined the catchment areas by TAZs (Traffic Analysis Zone) that are totally covered or partially covered by defined circles of each activity center in CAMPO 2035 Plan (see Map 2 ). Because the essential goal of improving jobs-housing balance is to reduce VMT, the catchment areas by TAZs with travel data can help planners and local municipalities to define appropriate ratios in relation to commuting benefits. In addition, 
the defined boundaries are more accurate to incorporate with "On the Map" tool in the Longitudinal Employer-Household Dynamics (LEHD).

\section{Map1 Catchment Areas of Activity Centers}

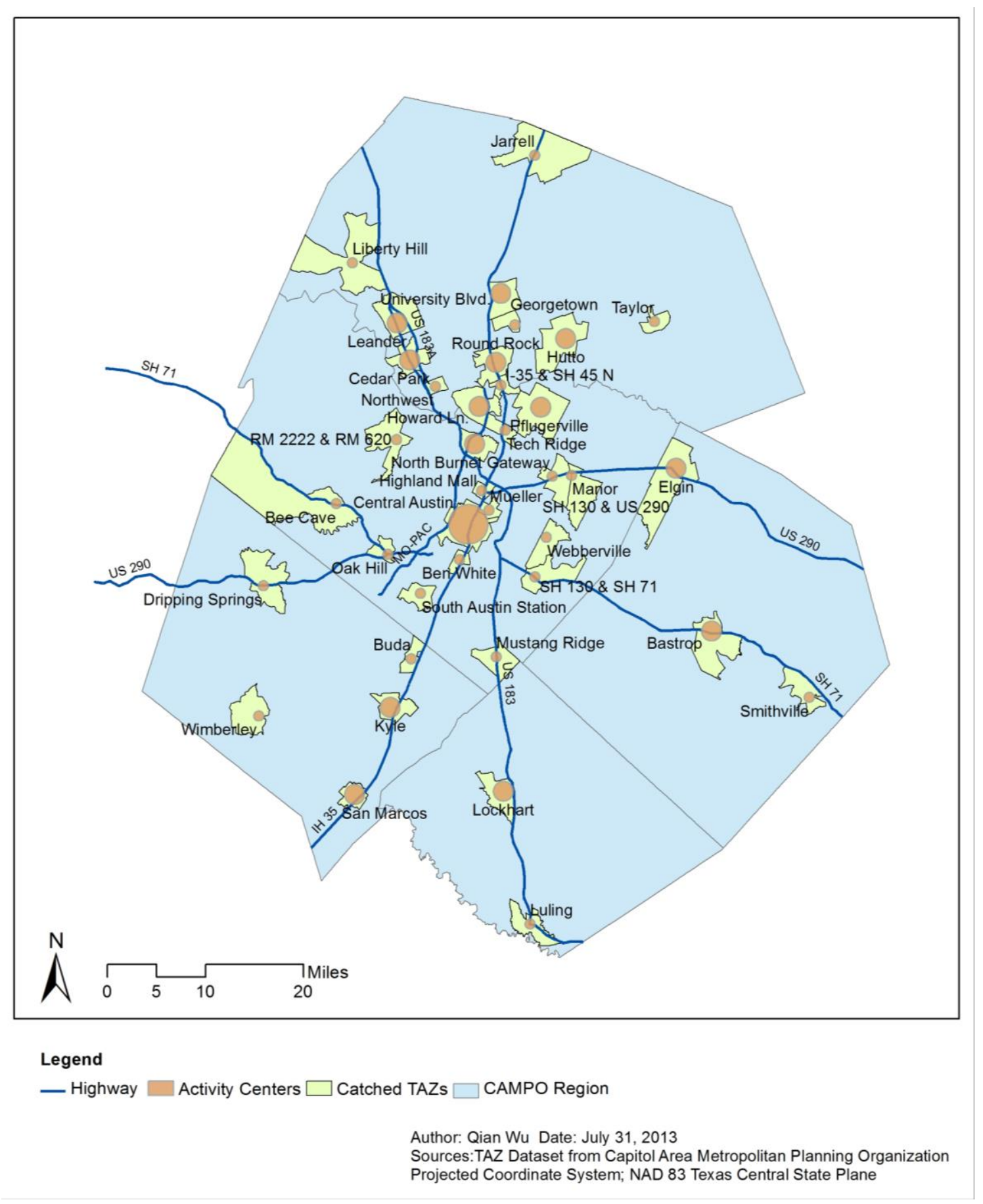




\subsection{Ways to Evaluate Jobs-housing Ratio and Dataset}

The literature has provided three ways to measure jobs-housing balance (JHB) in terms of jobs-housing ratio. The evaluation on JHB in Austin MSA should be feasible to acquire necessary data. This study will calculate jobs/household ratio (JHR), jobs-employed resident ratio (JER), and jobs-population ratios by using CAMPO TAZ (Traffic Analysis Zone) datasets in the year 2005 and 2010.

CAMPO TAZ dataset includes basic population and employment information of each TAZ. Details of employment and travel feature can be obtained from Longitudinal Employer-Household Dynamics (LEHD). LEHD is a program focusing on economic studies at the U.S. Census Bureau, which link administrative data from federal and state governments and the Census Bureau with data extracted from censuses and surveys. It provides detailed information about employment, earnings, race, age, occupation, and job flow which are available at different geographic levels (MSA, county, census tract, census block groups, and census block) (See Figure 5). Data is available from 2002 to 2011 (LHED, http://lehd.did.census.gov/led/). 


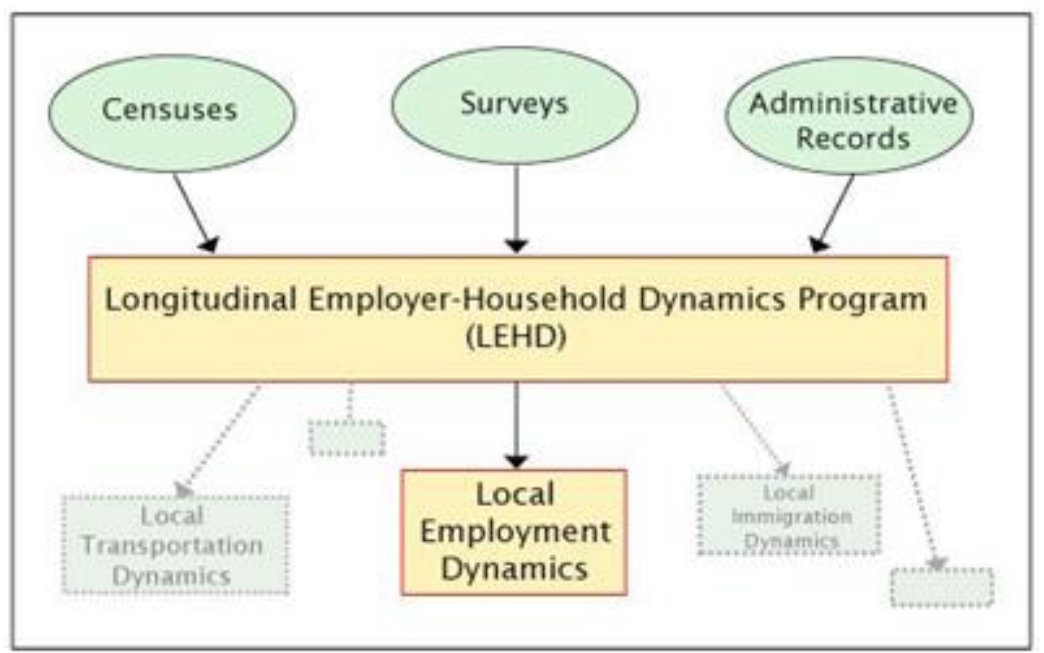

Figure 5 LHED Data Flow Chart (Source: http://lehd.did.census.gov/led/)

The 'On the Map' tool in the LHED program describes the distribution of jobs and workers by user specified geographies that can be imported from GIS shapefiles. The maps can show worker inflows and outflows and calculate labor efficiency (residents employed locally) and employment efficiency (workers reside locally) by defined areas. In addition, the tool also provides detailed information about worker movement regarding direction, destination, and travel distance of home-to- work trip and work-to-home trip. The LHED data is a good source and very useful to analyze the distribution of jobs and housing at local level. In addition, it generally outlines the degree of self-containment in the defined areas.

GIS data used in the analyses were downloaded from the City of Austin, Capital Area Council of Government, CAPCOG (Capitol Area Council of Government), and 
CAMPO website. Data obtained is listed below:

-Activity center shapefile (CAMPO Website);

-Metrorail shapefile (Capitol Metro website);

-Central Texas TAZ shapefile including demographics (CAMPO website);

- CAMPO Region shapefile (CAPCOG website);

- Data of jobs and housing distribution and worker inflow and outflow (LEHD website).

The analyses in GIS used the common projection system: NAD83, Texas Central

State Plane, Survey (feet).

\subsection{Analysis of Jobs-housing Ratios}

Before defining good jobs-housing ratios for activity centers, it is important to know the existing ratios and the information conveyed by these ratios. This section will calculate jobs-housing ratios for 38 activity centers in 2005 and 2010 as a basis for examining the applicability of jobs-housing ratios in land use policy in Central Texas.

\subsubsection{Jobs-housing balance Profile in Region}

The jobs-housing imbalance has been a critical issue in Central Texas. By 2010, almost half of all workers commute across county lines to reach workplaces (CAPCOG Central Texas Regional Data, 2013). The share of work trip distance longer than 50 miles increased 5\% from 2005 to 2010 in Austin Region (Table 6). Travis and Williamson Counties are the largest job pools, with large amounts of commuters from the north and 
southwest of the CAMPO region and central Austin (Figure 6 and Map 1). Figure 7 shows the general profile of travel distance and direction in the CAMPO region. The darkest green color and light yellow in radar charts represent shortest (less than 10 miles) and longest travel distance (greater than 50 miles) respectively, with the number of commuters in direction. Table 7 shows the changes in the share of local workers (workers residing locally), jobs-employed resident ratios and work-to-home trip distance in five counties in CAMPO region between 2005 and 2010. Travis and Williamson Counties experienced slight increases in jobs-housing balance. In contrast, the jobs-employed resident ratios of Bastrop, Hays, Caldwell Counties reduced between the 2005 and 2010, but commuter with trip distance greater than 10 miles increased greatly. According to Cervero's study, jobs- employed residents ratio between 0.8 and 1.25 indicates balance in jobs and housing (Cervero 1996). Williamson and Hays counties have relatively high jobs-employed resident ratios but the share of local workers is much lower than other counties. In other words, local job type cannot satisfy local residents. Conversely, Bastrop County is the highest self-contained community though it shows extreme imbalanced employed-residents ratio. Therefore, it seems that the jobs to housing ratios did not explain the exact spatial distribution of jobs and workers. However, the jobs-housing ratios at county level can provide basis reference for activity centers within each county. 
Table 6 Austin MSA Work to Home Travel Profile

\begin{tabular}{lcccc}
\hline \multicolumn{4}{c}{ Work to Home Travel Distance } \\
\hline & Count & Share & Count & Share \\
\hline Total Primary Jobs & 754,459 & $100.0 \%$ & 656,292 & $100.0 \%$ \\
Less than 10 miles & 306,265 & $40.6 \%$ & 306,212 & $46.7 \%$ \\
10 to 24 miles & 199,660 & $26.5 \%$ & 173,759 & $26.5 \%$ \\
25 to 50 miles & 52,927 & $7.0 \%$ & 43,278 & $6.6 \%$ \\
Greater than 50 miles & 195,607 & $25.9 \%$ & 133,043 & $20.3 \%$ \\
\hline
\end{tabular}

Data source: Longitudinal Employer-Household Dynamics, http://lehd.ces.census.gov/

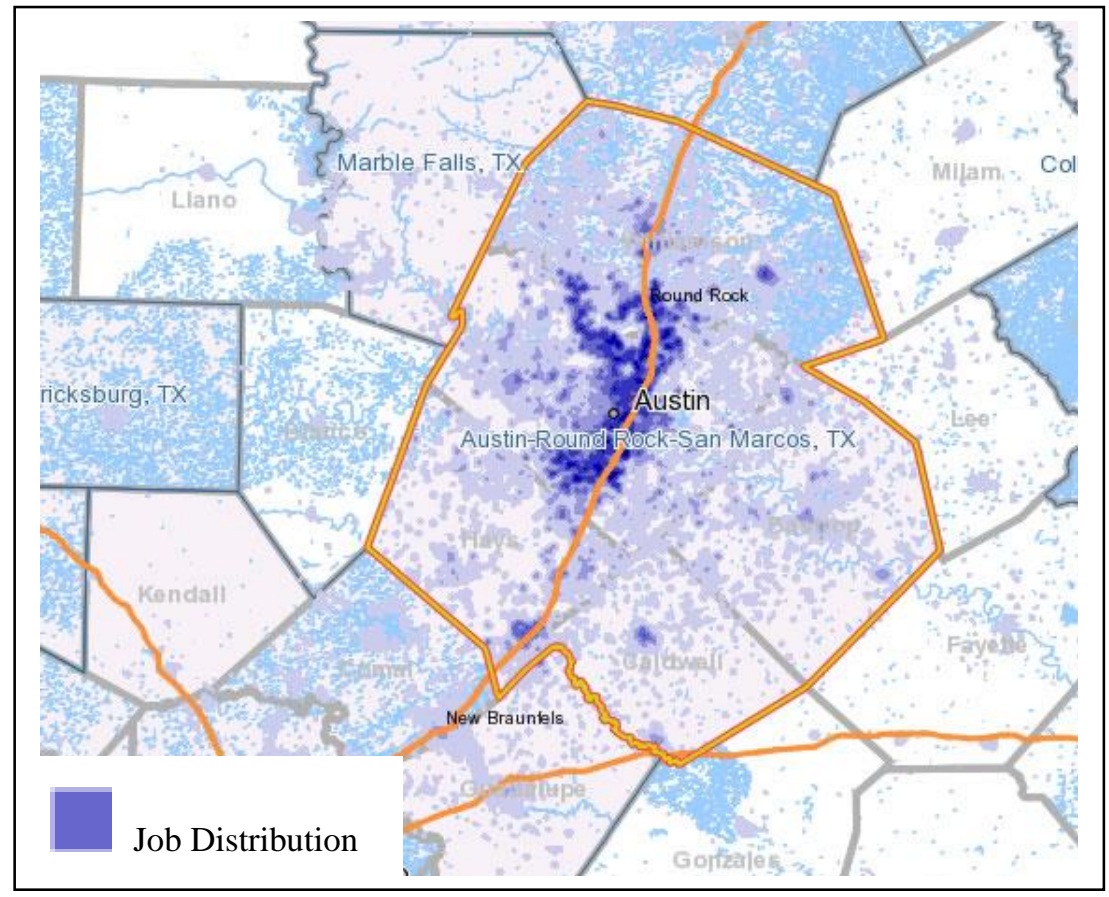

Figure 6 Job Distribution in CAMPO Region

Source: OntheMap http://onthemap.ces.census.gov/ 

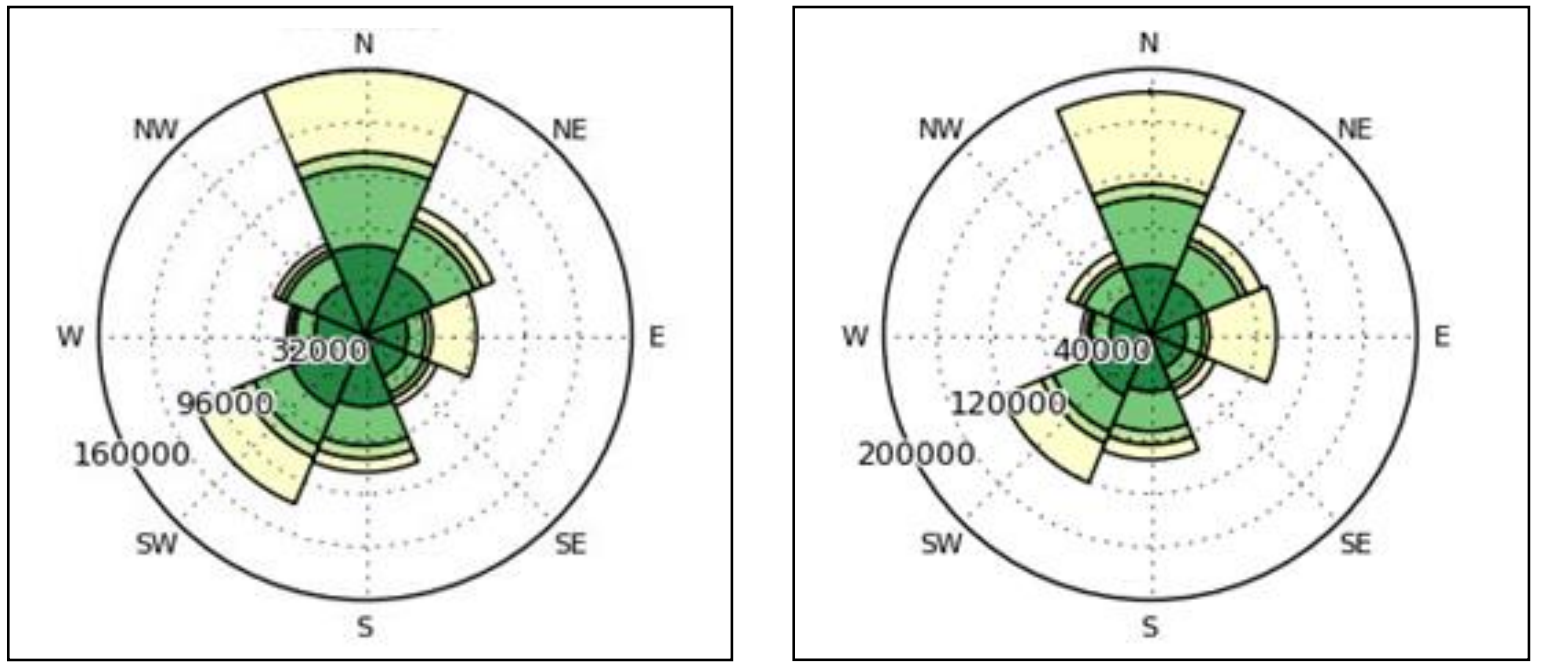

Figure7: Jobs Counts by Distance/Direction in 2005 and 2010(All workers CAMPO Region)

Source: OntheMap http://onthemap.ces.census.gov/

Table 7: Changes in Jobs-housing Ratio and Commute Distance

\begin{tabular}{|c|c|c|c|c|c|c|c|}
\hline County & Year & $\begin{array}{r}\text { Local } \\
\text { workers }\end{array}$ & Jobs & $\begin{array}{r}\text { Local } \\
\text { workers } \\
(\%)\end{array}$ & $\begin{array}{l}\text { Employed } \\
\text { Residents }\end{array}$ & JER & $\begin{array}{c}\text { Share of } \\
\text { Trip } \\
\text { Distance } \\
>10 \text { miles }\end{array}$ \\
\hline \multirow{2}{*}{ Travis } & 2005 & 314,591 & 560,377 & $56.1 \%$ & 406,810 & 1.38 & $26.6 \%$ \\
\hline & 2010 & 312,729 & 621,672 & $50.3 \%$ & 455,766 & 1.36 & $33.1 \%$ \\
\hline \multirow{2}{*}{ Williamson } & 2005 & 39,005 & 76,965 & $50.7 \%$ & 146,841 & 0.52 & $52.0 \%$ \\
\hline & 2010 & 49,916 & 109,649 & $45.5 \%$ & 175,448 & 0.62 & $56.0 \%$ \\
\hline \multirow{2}{*}{ Hays } & 2005 & 15,680 & 37,967 & $41.3 \%$ & 44,309 & 0.86 & $69.9 \%$ \\
\hline & 2010 & 15,355 & 40,631 & $37.8 \%$ & 59,971 & 0.68 & $77.5 \%$ \\
\hline \multirow{2}{*}{ Caldwell } & 2005 & 2,242 & 4,894 & $45.8 \%$ & 12,261 & 0.40 & $58.3 \%$ \\
\hline & 2010 & 2,313 & 5,512 & $42.0 \%$ & 15,921 & 0.35 & $64.6 \%$ \\
\hline \multirow{2}{*}{ Bastrop } & 2005 & 6,267 & 10,638 & $58.9 \%$ & 25,070 & 0.42 & $58.0 \%$ \\
\hline & 2010 & 6,570 & 12,489 & $52.6 \%$ & 31,763 & 0.39 & $62.5 \%$ \\
\hline
\end{tabular}

Data source: OntheMap http://onthemap.ces.census.gov/ 


\section{Map 2 Land Use Pattern in Central Austin}

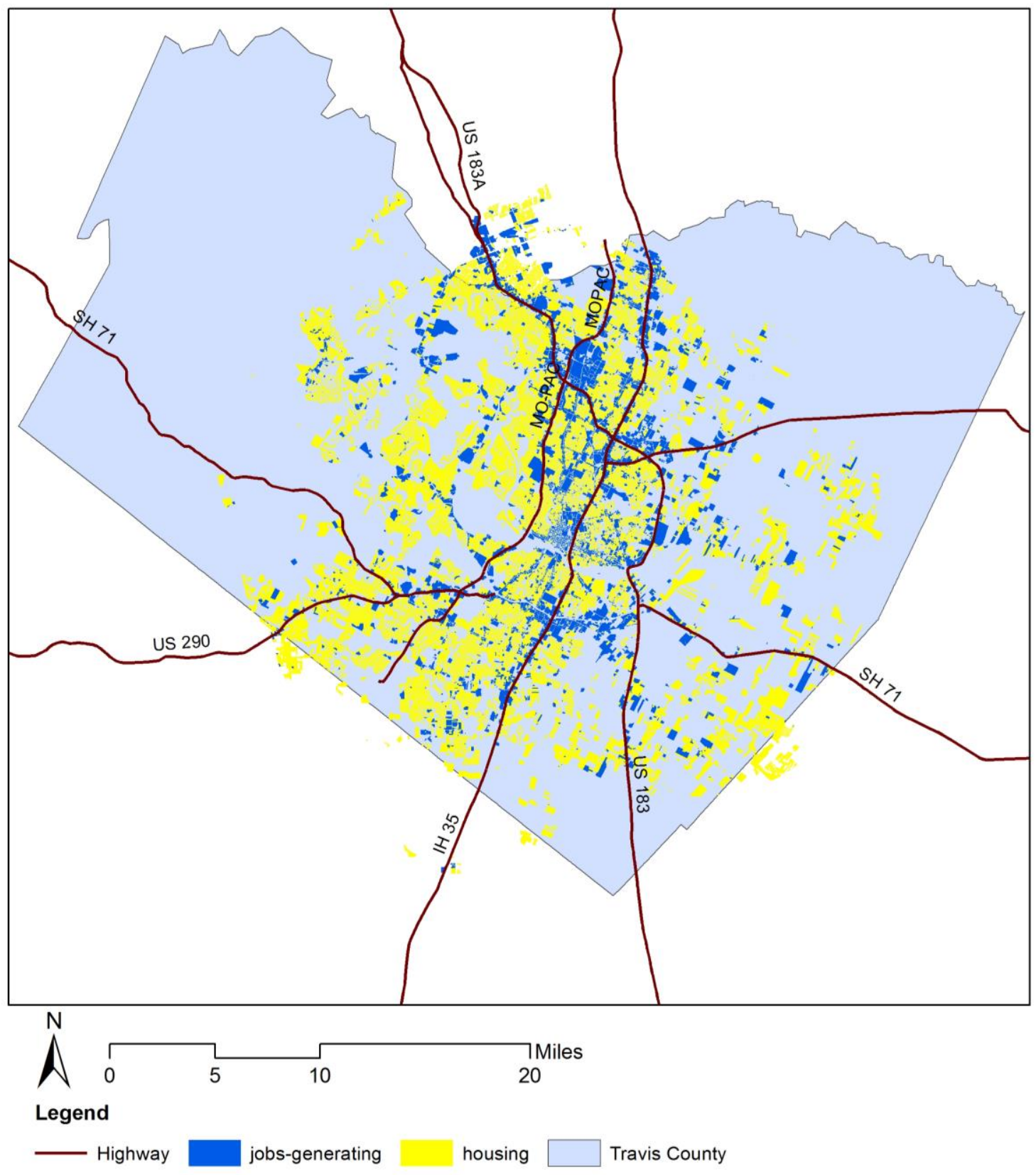

Author: Qian Wu Date: July 31, 2013

Sources: County boundary from CAPCOG website, land use from City of Austin website.

Projected Coordinate System; NAD 83 Texas Central State Plane 


\subsubsection{Jobs-housing Ratios of Activity Centers}

The study aggregated data from TAZs that are covered within activity centers and calculate jobs to household ratios (JHR) and jobs to population ratios (JPR) in 2005 and 2010. Jobs to employed-residents ratios (JER) were calculated by using the LEHD data. Particularly note that JPR is vulnerable in household size. The household size varies from 1.7 to 3.3. Thus, JPR is not a good measurement of jobs-housing balance.

Although there is no agreement of a good ratio and the literature review suggested that good jobs-housing ratios differ in geographic units and metropolitan size. Since the CAMPO region is a medium-sized metropolitan area like Portland (Table 8), this study drew from Peng's results, assuming that JHRs within 1.2 to 2.8 are balanced ratios. JERs and JHRs were grouped based on the Peng's definition.

Table 8 Region Profiles of Portland and Austin

\begin{tabular}{lcc}
\hline Statistics & $\begin{array}{c}\text { Portland-Vancouver-Hillsboro, } \\
\text { Oregon }\end{array}$ & $\begin{array}{c}\text { Austin-Round Rock-San } \\
\text { Marcos, Texas }\end{array}$ \\
\hline Total Population & $1,789,580$ & $1,716,289$ \\
\hline $\begin{array}{l}\text { Population } \\
\text { Density (per sq. } \\
\text { mile) }\end{array}$ & 406.8 & 406.7 \\
\hline $\begin{array}{l}\text { Area (Land)(sq. } \\
\text { miles) }\end{array}$ & $4,481.31$ & $4,280.08$ \\
\hline
\end{tabular}

Data source: American Fact Finder 
Figure 8 shows activity centers with improved jobs-housing balance ratios from 2005 to 2010; Figure 9 displays activity centers that kept balanced ratios in 2005 and 2010; Figure 10 presents the activity centers with imbalanced ratios either in 2005 or 2010. Plots in three figures have similar shapes, thus the measurements of JHR and JER share the similar interpretation of jobs-housing balance. Similar negative correlations $(-0.31)$ between jobs-household ratios, jobs to employed-residents ratios and local residing workers are found. Conversely, there is a positive correlation (0.3) between jobs to employed-residents ratios and local employed residents, which mean that improvement in jobs to employed-residents ratios could increase self-containment in communities because of more jobs opportunities.

In order to test the reality of jobs-housing ratios, more information about distribution of jobs and housing within each center was extracted from LEHD by using the OntheMap tool. Table 10 presents the JERs, self-containment, and travel distance larger than 10 miles. Currently, all the activity centers have pretty low employment efficiency (share of workers reside locally below 20\%) and labor force efficiency (share of residents employed locally below 20\%). Some activity centers with assumed balanced jobs to household ratios (based on Peng's definition) have low degrees of self-containment and larger amounts of long distance commuters, such as Georgetown, Taylor, Bastrop, Bee Cave, and Buda. Over half of workers in all the activity centers endure long distance work-to-home trips (lager than 10 miles). Base on the data collected, 
no clear relationship was found between jobs-employed resident ratios and self-containment, jobs-employed resident ratios and commute distance. Some activity centers with perfect ratios also show very low self-containment, such as Oak Hill, RM 2222 \& RM 620, Taylor, and Howard Ln centers. There might be a severe mismatch between jobs opportunities and workers' skills, the salary of workers and housing price.

Jobs-housing ratios in activity centers should be higher than average ratios of counties because land uses in centers are typically more compact and mixed use than surrounding areas. For example, the planning experience in the D.C metropolitan area suggested an appropriate range of jobs-household ratio from 3.0 to 6.0 for mixed-use centers. In 2005, four transit centers in the Washington region --Rosslyn, Ballston, Bethesda, and Silver Springs-- have pretty high ratios of jobs to household between 3.4 and 6.0 (Fairfax County Department of Planning \& Zoning 2012, p. ii). Peng's criteria for jobs-housing ratio might not be suitable for activity centers. Because of differences in measured scales, the spline-function model needs to be tested in local context. However, a pretty low jobs-household ratio of 1.2 was recommended for activity centers within 4 miles of transits stations in the Sacramento Region ((MTP/SCS 2035 Plan 2012, p 3-38). Identifying good target ratios for activity centers in Central Texas should consider more factors, such as VMT of work trip and non-work trip, inner and out trip.

Overall, existing jobs-household ratios of activity centers cannot exactly explain the real jobs-housing balance based on data applied in this study. Activity centers with high 
ratios share similar poor self-containment and long distance commute as these with low ratios. Increase in jobs-household ratio is not associated with reduction in commute distance. Beyond these numbers of jobs to household, more factors that influence jobs-housing balance should be explored.

Map 3 Jobs-household Ratios of Activity Centers 2005

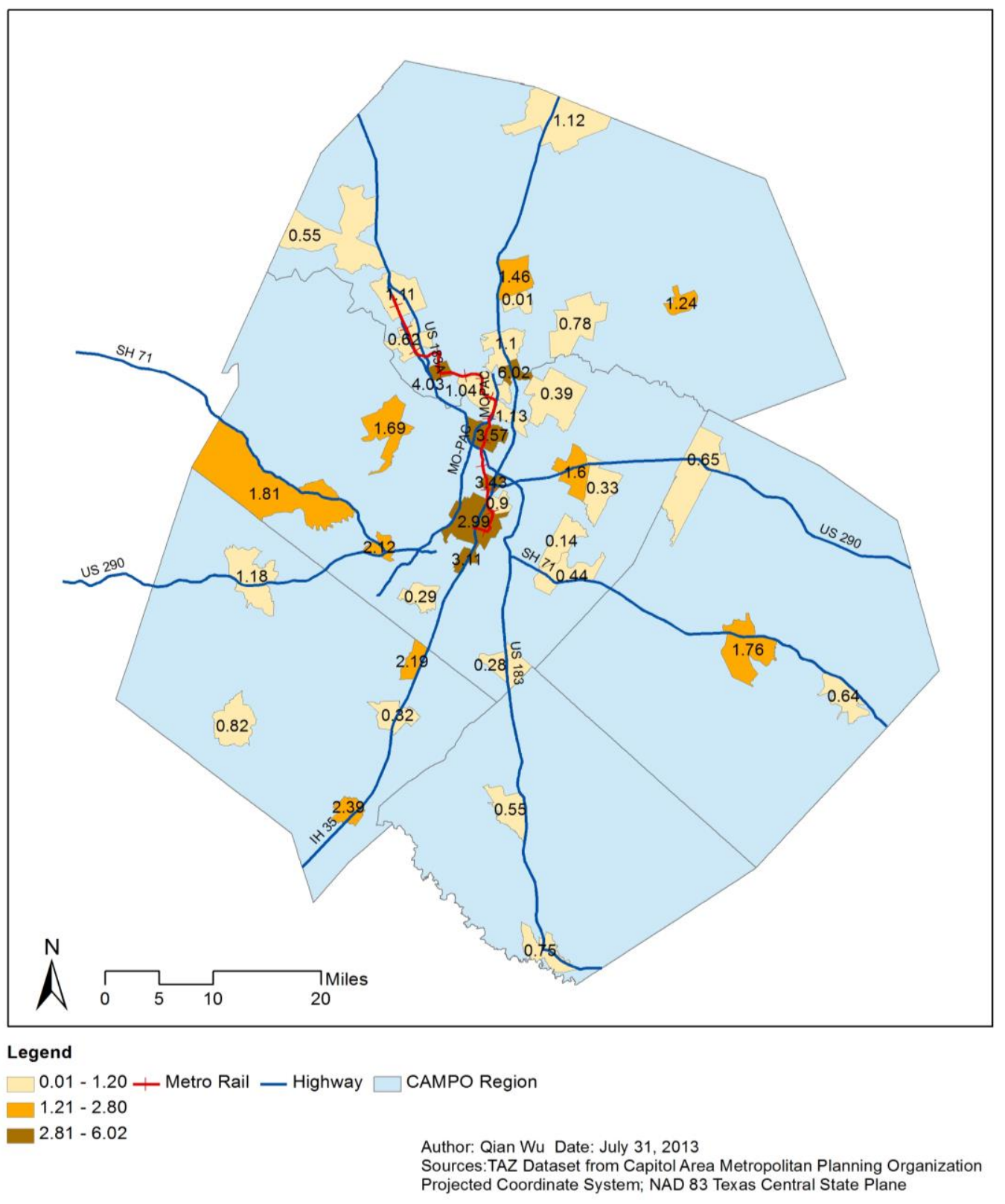


Map 4 Jobs-household Ratios of Activity Centers 2010

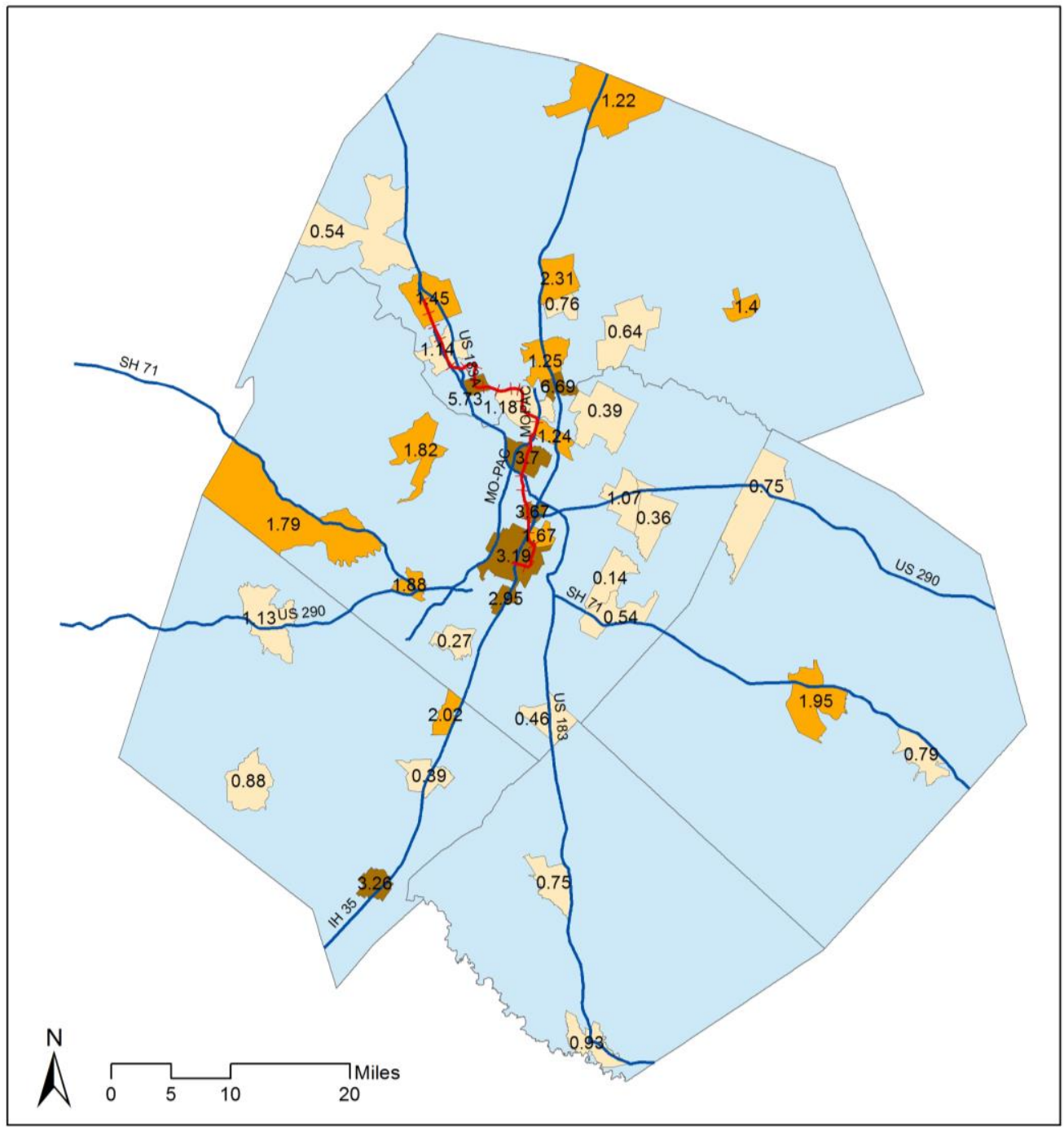

Legend

$\square 0.14-1.20+$ Metro Rail — Highway $\square$ CAMPO Region

$1.21-2.8$

$2.81-6.69$

Author: Qian Wu Date: July 31, 2013

Sources:TAZ Dataset from Capitol Area Metropolitan Planning Organization Projected Coordinate System; NAD 83 Texas Central State Plane 
Table 9 Jobs-housing Ratios in Activity Centers (2005-2010)

\begin{tabular}{|c|c|c|c|c|c|c|c|c|}
\hline Name & Growth Type & $\begin{array}{l}2010 \\
\text { Average } \\
\text { Household } \\
\text { Size }\end{array}$ & JER 05 & JHR05 & JPR05 & JER 10 & JHR10 & JPR 10 \\
\hline Central Austin & Large & 2.8 & 5.03 & 2.99 & 1.41 & 5.67 & 3.19 & 1.49 \\
\hline North Burnet Gateway & Medium & 2.2 & 2.79 & 3.57 & 1.67 & 2.45 & 3.70 & 1.67 \\
\hline Howard Ln. & Medium & 2.6 & 1.17 & 1.04 & 0.42 & 0.96 & 1.18 & 0.47 \\
\hline Leander & Medium & 2.9 & 0.60 & 1.11 & 0.38 & 0.40 & 1.45 & 0.50 \\
\hline Lockhart & Medium & 2.7 & 0.37 & 0.55 & 0.21 & 0.45 & 0.75 & 0.28 \\
\hline Cedar Park & Medium & 3.0 & 0.59 & 0.62 & 0.20 & 0.32 & 1.14 & 0.38 \\
\hline Round Rock & Medium & 2.5 & 0.64 & 1.10 & 0.38 & 0.59 & 1.25 & 0.43 \\
\hline Georgetown & Medium & 2.4 & 1.84 & 1.46 & 0.52 & 2.02 & 2.31 & 0.82 \\
\hline Kyle & Medium & 2.8 & 1.36 & 0.32 & 0.10 & 0.32 & 0.39 & 0.12 \\
\hline Bastrop & Medium & 2.5 & 1.64 & 1.76 & 0.68 & 1.60 & 1.95 & 0.75 \\
\hline San Marcos & Medium & 1.7 & 1.94 & 2.39 & 0.67 & 1.83 & 3.26 & 0.94 \\
\hline Pflugerville & Medium & 3.0 & 0.11 & 0.39 & 0.13 & 0.65 & 0.39 & 0.13 \\
\hline Elgin & Medium & 2.9 & 0.84 & 0.65 & 0.23 & 0.83 & 0.75 & 0.26 \\
\hline Hutto & Medium & 3.1 & 0.52 & 0.78 & 0.25 & 0.43 & 0.64 & 0.21 \\
\hline Northwest & Small & 1.8 & 2.51 & 4.03 & 1.49 & 2.03 & 5.73 & 2.17 \\
\hline Highland Mall & Small & 2.3 & 5.00 & 3.43 & 1.37 & 4.95 & 3.67 & 1.49 \\
\hline Taylor & Small & 3.3 & 1.15 & 1.24 & 0.42 & 0.96 & 1.40 & 0.48 \\
\hline RM 2222 \& RM 620 & Small & 2.5 & 2.48 & 1.69 & 0.69 & 1.19 & 1.82 & 0.75 \\
\hline
\end{tabular}


Table 9 (continued)

\begin{tabular}{|c|c|c|c|c|c|c|c|c|}
\hline Smithville & Small & 2.5 & 0.49 & 0.64 & 0.25 & 0.39 & 0.79 & 0.30 \\
\hline Tech Ridge & Small & 2.6 & 0.42 & 1.13 & 0.42 & 0.43 & 1.24 & 0.48 \\
\hline Liberty Hill & Small & 2.9 & 0.43 & 0.55 & 0.18 & 0.34 & 0.54 & 0.18 \\
\hline I-35 \& SH 45 N & Small & 2.8 & 3.40 & 6.02 & 2.13 & 7.56 & 6.69 & 2.38 \\
\hline Mueller & Small & 2.7 & 0.76 & 0.90 & 0.33 & 0.59 & 1.67 & 0.64 \\
\hline Jarrell & Small & 2.8 & 0.37 & 1.12 & 0.39 & 0.71 & 1.22 & 0.43 \\
\hline SH $130 \&$ SH 71 & Small & 3.2 & 0.31 & 0.44 & 0.14 & 0.38 & 0.54 & 0.16 \\
\hline Oak Hill & Small & 2.6 & 2.05 & 2.12 & 0.81 & 1.19 & 1.88 & 0.72 \\
\hline Luling & Small & 2.8 & 0.04 & 0.75 & 0.28 & 0.05 & 0.93 & 0.34 \\
\hline South Austin Station & Small & 2.6 & 0.46 & 0.29 & 0.11 & 0.20 & 0.27 & 0.10 \\
\hline Mustang Ridge & Small & 3.1 & 0.20 & 0.28 & 0.09 & 0.23 & 0.46 & 0.15 \\
\hline SH 130 \& US 290 & Small & 2.6 & 0.16 & 1.60 & 0.52 & 0.18 & 1.07 & 0.34 \\
\hline Manor & Small & 2.7 & 0.33 & 0.33 & 0.11 & 0.37 & 0.36 & 0.12 \\
\hline Ben White & Small & 2.6 & 2.03 & 3.11 & 1.37 & 1.55 & 2.95 & 1.22 \\
\hline Bee Cave & Small & 2.6 & 2.34 & 1.81 & 0.69 & 2.65 & 1.79 & 0.69 \\
\hline Dripping Springs & Small & 2.8 & 0.62 & 1.18 & 0.41 & 0.70 & 1.13 & 0.40 \\
\hline Buda & Small & 2.4 & 1.21 & 2.19 & 0.79 & 0.56 & 2.02 & 0.71 \\
\hline University Blvd. & Small & 2.3 & 1.49 & 0.01 & 0.00 & 9.63 & 0.76 & 0.27 \\
\hline Webberville & Small & 3.5 & 0.12 & 0.14 & 0.04 & 0.12 & 0.14 & 0.04 \\
\hline Wimberley & Small & 2.4 & 0.52 & 0.82 & 0.35 & 0.55 & 0.88 & 0.37 \\
\hline
\end{tabular}




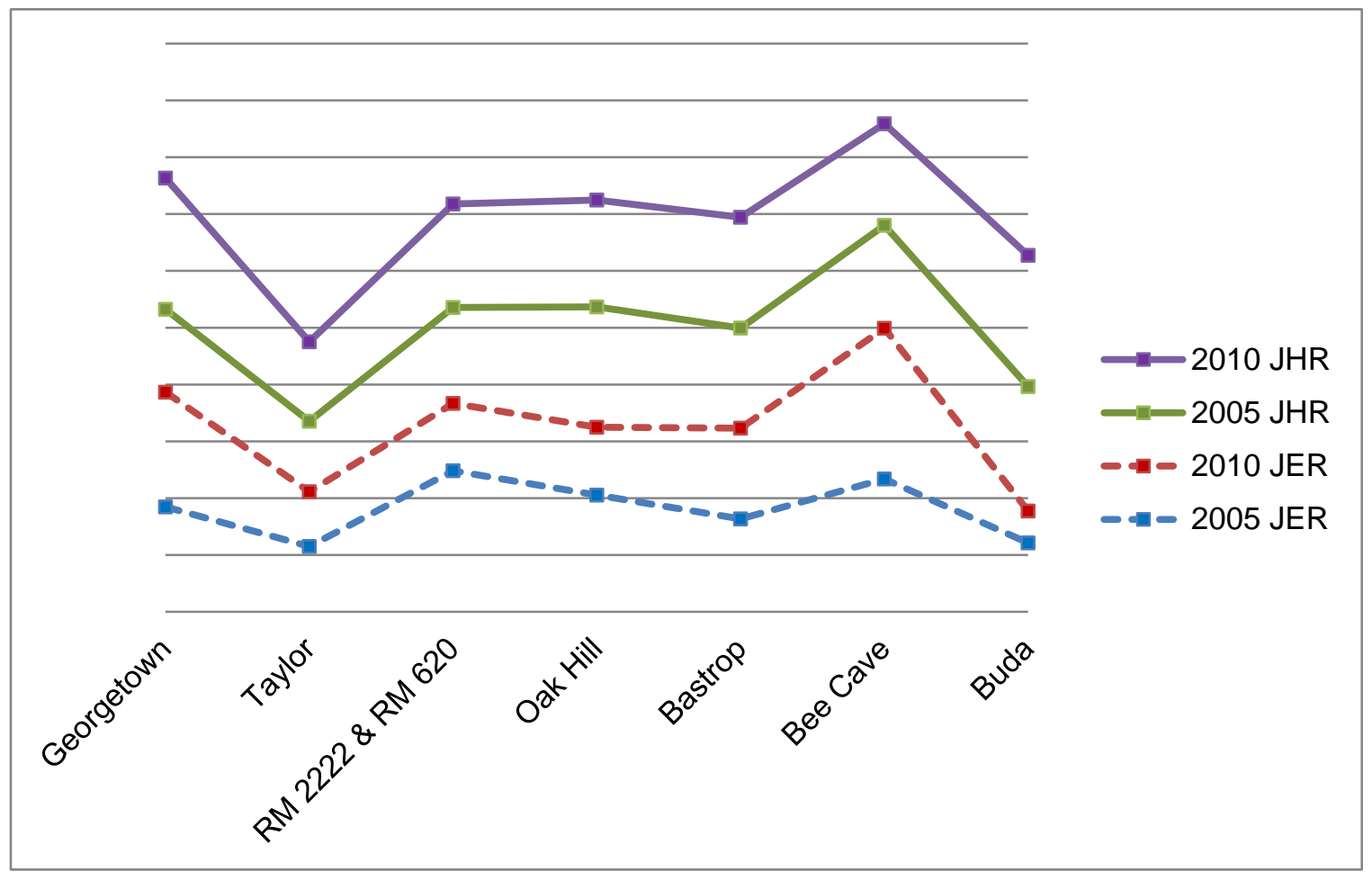

Figure 8 Ratios Portraying Jobs-housing Balance in Activity Centers

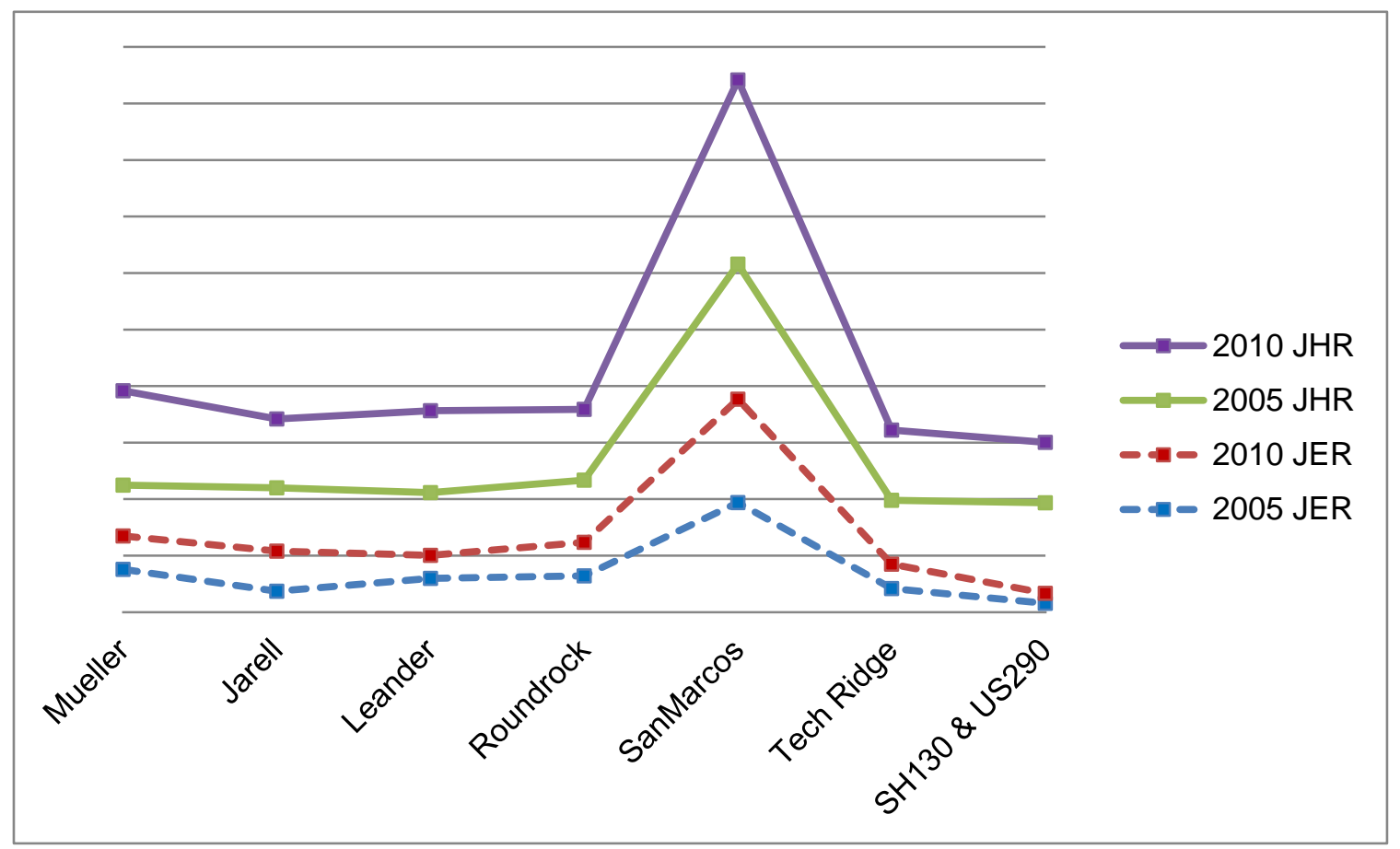

Figure 9 Ratios Portraying Jobs-housing Balance in Activity (JHRs keep in the range 1.2-2.8) 


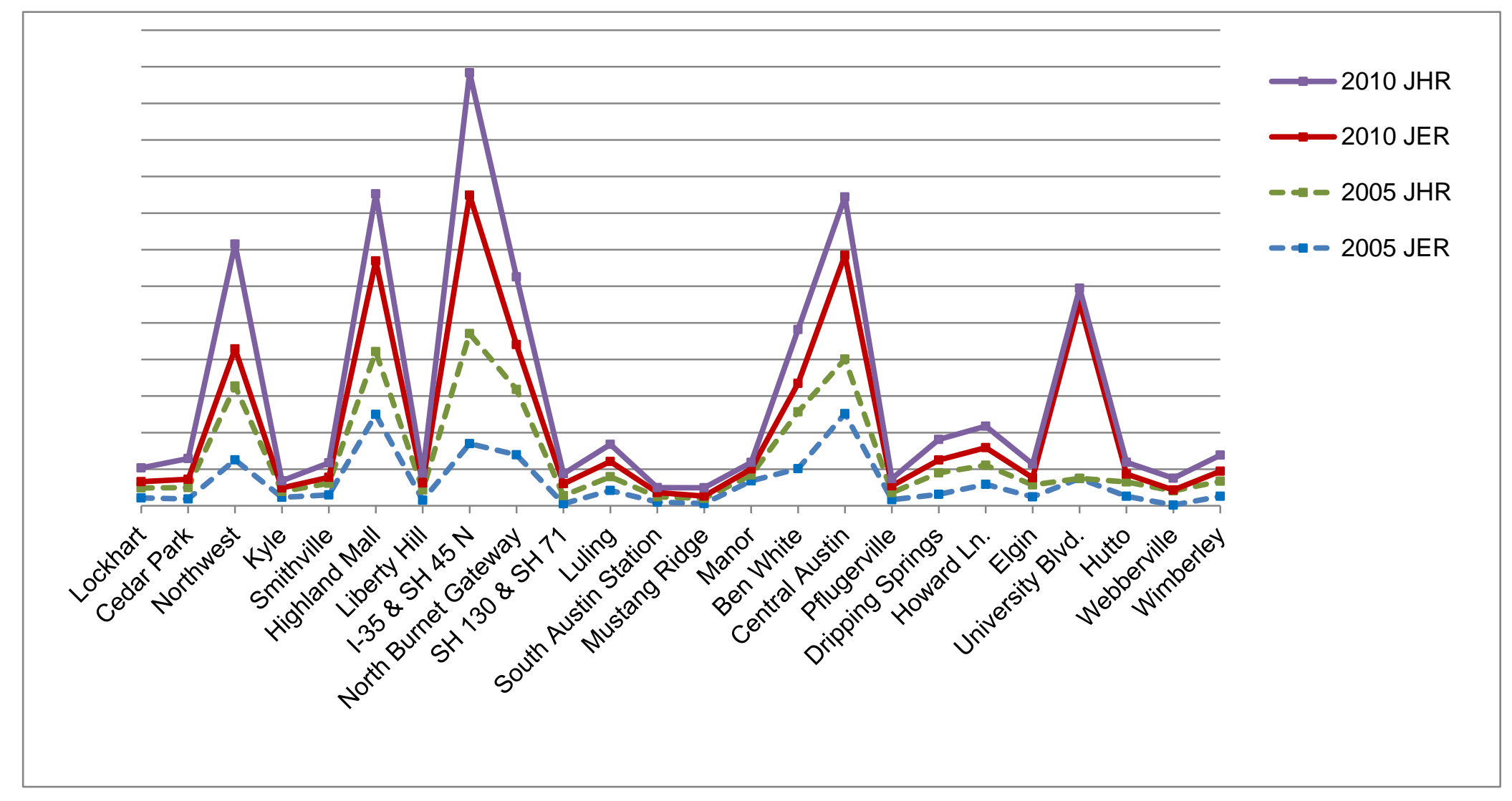

Figure 10 Ratios Portraying Jobs-housing Balance in Activity (JHRs keep out of the range 1.2-2.8) 
Table 10 Jobs-employed Resident Ratios and Travel Distance

\begin{tabular}{|c|c|c|c|c|c|c|c|}
\hline \multirow{2}{*}{$\begin{array}{l}\text { Activity Center } \\
\text { Year }\end{array}$} & \multirow[t]{2}{*}{$\begin{array}{l}\text { Growth } \\
\text { Type }\end{array}$} & \multicolumn{2}{|c|}{$\begin{array}{l}\text { Job-employed } \\
\text { resident } \\
\text { ratio(JER) }\end{array}$} & \multicolumn{2}{|c|}{ Local workers (\%) } & \multicolumn{2}{|c|}{$\begin{array}{l}\text { Share of work-home } \\
\text { trip }>10 \text { miles }\end{array}$} \\
\hline & & 2005 & 2010 & 2005 & 2010 & 2005 & 2010 \\
\hline Smithville & Small & 0.59 & 0.32 & $20.1 \%$ & $27.7 \%$ & $60.1 \%$ & $51.4 \%$ \\
\hline Lockhart & Medium & 0.43 & 0.34 & $30.1 \%$ & $25.0 \%$ & $51.5 \%$ & $58.9 \%$ \\
\hline Lu ling & Small & 0.84 & 0.83 & $28.8 \%$ & $23.8 \%$ & $64.1 \%$ & $68.8 \%$ \\
\hline Elgin & Medium & 0.49 & 0.39 & $27.0 \%$ & $20.9 \%$ & $53.0 \%$ & $62.9 \%$ \\
\hline Wimberley & Small & 0.52 & 0.55 & $23.0 \%$ & $18.4 \%$ & $49.7 \%$ & $55.2 \%$ \\
\hline Pflugerville & Medium & 0.33 & 0.37 & $18.5 \%$ & $15.4 \%$ & $37.0 \%$ & $42.2 \%$ \\
\hline Bastrop & Medium & 1.64 & 1.60 & $17.4 \%$ & $13.5 \%$ & $56.8 \%$ & $60.3 \%$ \\
\hline Taylor & Small & 1.15 & 0.96 & $17.0 \%$ & $12.7 \%$ & $49.0 \%$ & $56.1 \%$ \\
\hline San Marcos & Medium & 1.94 & 1.83 & $14.5 \%$ & $10.9 \%$ & $53.8 \%$ & $60.9 \%$ \\
\hline Liberty Hill & Small & 0.31 & 0.38 & $12.4 \%$ & $10.0 \%$ & $60.4 \%$ & $69.3 \%$ \\
\hline Round Rock & Medium & 0.64 & 0.59 & $14.4 \%$ & $9.8 \%$ & $44.4 \%$ & $53.3 \%$ \\
\hline Cedar Park & Medium & 0.37 & 0.45 & $12.5 \%$ & $9.2 \%$ & $53.4 \%$ & $58.2 \%$ \\
\hline Leander & Medium & 0.60 & 0.40 & $7.9 \%$ & $7.8 \%$ & $62.8 \%$ & $59.2 \%$ \\
\hline Dripping Springs & Small & 0.62 & 0.70 & $7.1 \%$ & $7.4 \%$ & $65.6 \%$ & $69.2 \%$ \\
\hline \multicolumn{8}{|l|}{ South Austin } \\
\hline Station & Small & 0.20 & 0.23 & $7.6 \%$ & $7.4 \%$ & $54.2 \%$ & $63.0 \%$ \\
\hline Central Austin & Large & 5.03 & 5.67 & $8.6 \%$ & $7.3 \%$ & $53.2 \%$ & $59.0 \%$ \\
\hline Kyle & Medium & 0.46 & 0.20 & $5.7 \%$ & $6.4 \%$ & $64.2 \%$ & $65.4 \%$ \\
\hline Hutto & Medium & 0.52 & 0.43 & $8.0 \%$ & $6.2 \%$ & $52.8 \%$ & $61.5 \%$ \\
\hline
\end{tabular}


Table 10 (continued)

\begin{tabular}{llllllll} 
Georgetown & Medium & 1.84 & 2.02 & $7.8 \%$ & $5.7 \%$ & $58.3 \%$ & $50.3 \%$ \\
Jarell & Small & 0.37 & 0.71 & $6.3 \%$ & $5.7 \%$ & $76.8 \%$ & $80.2 \%$ \\
Webberville & Small & 0.04 & 0.05 & $4.8 \%$ & $5.0 \%$ & $69.0 \%$ & $65.0 \%$ \\
Tech Ridge & Small & 0.42 & 0.43 & $3.0 \%$ & $3.3 \%$ & $52.6 \%$ & $60.3 \%$ \\
North Burnet & & & & & & & \\
Gateway & Medium & 2.79 & 2.45 & $3.8 \%$ & $3.2 \%$ & $45.6 \%$ & $55.1 \%$ \\
Buda & Small & 1.21 & 0.56 & $4.0 \%$ & $2.8 \%$ & $60.7 \%$ & $64.0 \%$ \\
Bee Cave & Small & 2.34 & 2.65 & $2.3 \%$ & $2.7 \%$ & $60.1 \%$ & $59.9 \%$ \\
Oak Hill & Small & 2.05 & 1.19 & $2.7 \%$ & $2.6 \%$ & $58.0 \%$ & $57.4 \%$ \\
Howard Ln. & Medium & 1.17 & 0.96 & $2.8 \%$ & $2.6 \%$ & $49.4 \%$ & $46.2 \%$ \\
Mueller & Small & 0.76 & 0.59 & $2.4 \%$ & $2.3 \%$ & $61.3 \%$ & $63.5 \%$ \\
Ben White & Small & 2.03 & 1.55 & $2.0 \%$ & $2.2 \%$ & $55.8 \%$ & $59.0 \%$ \\
RM 2222 \& RM 620 & Small & 2.48 & 1.19 & $1.8 \%$ & $1.8 \%$ & $52.6 \%$ & $61.0 \%$ \\
Manor & Small & 1.36 & 0.32 & $2.1 \%$ & $1.3 \%$ & $48.9 \%$ & $71.2 \%$ \\
Mustang Ridge & Small & 0.12 & 0.12 & $0.0 \%$ & $1.3 \%$ & $78.1 \%$ & $76.9 \%$ \\
I-35 \& SH 45 N & Small & 3.40 & 7.56 & $1.5 \%$ & $1.1 \%$ & $41.5 \%$ & $44.1 \%$ \\
Highland Mall & Small & 5.00 & 4.95 & $1.2 \%$ & $1.0 \%$ & $57.6 \%$ & $63.9 \%$ \\
Northwest & Small & 2.51 & 2.03 & $0.5 \%$ & $1.0 \%$ & $57.2 \%$ & $54.1 \%$ \\
SH 130 \& SH 71 & Small & 0.11 & 0.65 & $2.8 \%$ & $0.8 \%$ & $59.7 \%$ & $55.0 \%$ \\
SH130 \& US290 & Small & 0.16 & 0.18 & $0.0 \%$ & $0.4 \%$ & $61.2 \%$ & $70.0 \%$ \\
University Blvd. & Small & 1.49 & 9.63 & $0.0 \%$ & $0.1 \%$ & $68.2 \%$ & $69.6 \%$ \\
\hline
\end{tabular}


Since jobs-employed resident ratio is the best measurement to represent the true jobs-housing balance, this study will estimate the target ratios for activity centers. Three types of activity centers will serve for different purposes based on their size and locations. As mentioned before, inter-county work trips take up large amounts of VMT in CAMPO region. The development of activity centers aims to reduce external work trips across counties and improve jobs-housing balance within counties. Activity centers should accommodate larger proportion of jobs and housing than other places in the CAMPO region.

Good jobs-housing ratios vary in locality. Many previous studies use regional ratios as baseline. For example, SACG defines the appropriate ratio by using $20 \%$ fluctuation of regional ratio (SACG 2001). Cervero applies a standard deviation of 0.5 based on the regional ratio of 1.01 (Cervero 1996). Similarly, Fairfax County identifies the ratios for TOD centers depending on empirical ratios in D.C. region (Fairfax County Department of Planning \& Zoning 2012). According to LHED, the jobs-employed resident ratio of the CAMPO region was 1.1 in 2010. This report draws from the methods of SACG, Cervero (1996) and Fairfax County of Washington D.C. and estimate jobs-housing balance ratios for activity centers based on criteria below.

\section{Small centers:}

-The baseline of jobs-employed resident ratios for all the centers should achieve self-containment with a ratio of 1.0 because the small centers target at local residents. 
-Centers with TOD sites and high transit accessibility, the ratio could be higher than other small centers, but the maximum ratio is the 2.0. If the existing ratios show extreme imbalance, and the share of current local residing workers in the centers are too low (such as University Blvd. Highland Mall, and I-35 \& SH 45 N), the target ratios should be reduced.

\section{Medium Centers:}

-Medium centers with rail station sites should utilize the advantage of transit and accommodate more jobs. Puget Sound Regional Council in Washington found that employment density with 25 per acre ensures high speed transit ridership. Empirical studies of TOD development in the U.S. show that the residential densities for light rail served TOD vary from 7 to 15 units per acre (TCRP Report 102, 2004). Based on the assumption of 1.5 workers per housing unit, a threshold jobs-employed resident ratio could be 1.1 to 2.3 . This range could be adjusted based on the average jobs-employed resident ratio of the CAMPO region.

-The minimum ratios for medium centers could be $20 \%$ higher than average regional ratio of 1.1 since medium centers serve for regional employment and residents.

- For medium size centers without TOD, the maximum ratios could be $50 \%$ higher than regional ratios.

The Large center:

-The central Austin should increase housing supply for workers and reduce the 
jobs-employed resident ratio. In Washington D.C., the jobs-household ratios of mixed land use centers around transit station are between 3.0 and 6.0 (Fairfax County Department of Planning \& Zoning 2012). Currently, the jobs-employed resident ratio of central Austin is 5.7, representing an extremely imbalanced jobs and housing. According to Washington D.C., the threshold of jobs-household ratio for central Austin could be 6.0. Since the majority of workers in central Austin live in cohabitant housing, a ceiling ratio of jobs-employed resident is translated from jobs-household ratio of 6.0 based on two workers per household. Table 11 expresses transit accessibility and the target jobs-employed resident ratios for activity centers in 2040. 
Table 11 Target Jobs-employed Resident Ratios of Activity Centers

\begin{tabular}{|c|c|c|c|c|c|c|c|c|c|}
\hline Name & $\begin{array}{l}\text { Growth } \\
\text { Type }\end{array}$ & County & $\begin{array}{l}\text { Rail } \\
\text { stop }\end{array}$ & $\begin{array}{l}\text { TOD } \\
\text { Site }\end{array}$ & $\begin{array}{l}\text { Vacant } \\
\text { (acres) }\end{array}$ & $\begin{array}{l}\text { Mixed } \\
\text { use } \\
\text { (acres) }\end{array}$ & $\begin{array}{l}\text { Stop } \\
\text { density }\end{array}$ & $\begin{array}{l}2010 \\
\text { JER }\end{array}$ & $\begin{array}{l}\text { Target } \\
\text { JER }\end{array}$ \\
\hline Central Austin & Large & Travis & 1 & 1 & 250.97 & 1957 & 58.89 & 5.67 & $2.0-3.0$ \\
\hline North Burnet Gateway & Medium & Travis & 1 & 0 & 291.89 & 194 & 18.47 & 2.45 & $1.6-2.0$ \\
\hline Georgetown & Medium & Williamson & 0 & 0 & 1197.91 & 281 & 0.00 & 2.02 & $1.3-1.6$ \\
\hline San Marcos & Medium & Hays & 0 & 0 & 192.39 & 188 & 0.00 & 1.83 & $1.3-1.6$ \\
\hline Bastrop & Medium & Bastrop & 0 & 0 & 1552.51 & 16 & 0.00 & 1.60 & $1.3-1.6$ \\
\hline Howard Ln. & Medium & Travis & 1 & 0 & 2108.31 & & 0.32 & 0.96 & $1.3-2.0$ \\
\hline Round Rock & Medium & Williamson & 0 & 0 & 171.44 & 134 & 0.00 & 0.59 & $1.3-1.6$ \\
\hline Cedar Park & Medium & Williamson & 0 & 0 & 526.30 & 453 & 0.00 & 0.45 & $1.3-1.6$ \\
\hline Hutto & Medium & Williamson & 0 & 0 & 1767.54 & 0 & 0.00 & 0.43 & $1.3-2.0$ \\
\hline Leander & Medium & Williamson & 1 & 0 & 1180.98 & 0 & 2.55 & 0.40 & $1.3-2.0$ \\
\hline Elgin & Medium & Bastrop & 0 & 0 & 2002.98 & 78 & 0.00 & 0.39 & $1.3-1.6$ \\
\hline Pflugerville & Medium & Travis & 0 & 0 & 1679.73 & 90 & 0.00 & 0.37 & $1.3-1.6$ \\
\hline Lockhart & Medium & Caldwell & 0 & 0 & 1060.59 & 48 & 0.00 & 0.34 & $1.3-1.6$ \\
\hline Kyle & Medium & Hays & 0 & 0 & 902.13 & 84 & 0.00 & 0.20 & $1.3-1.6$ \\
\hline University Blvd. & Small & Williamson & 0 & 0 & 817.92 & 0 & 0.00 & 9.63 & $1.6-2.0$ \\
\hline I-35 \& SH 45 N & Small & Travis & 0 & 0 & 65.54 & 210 & 0.00 & 7.56 & $1.0-1.5$ \\
\hline Highland Mall & Small & Travis & 1 & 1 & 0.00 & 180 & 22.93 & 4.95 & $1.0-2.0$ \\
\hline Bee Cave & Small & Travis & 0 & 0 & 422.81 & 0 & 0.00 & 2.65 & $1.0-1.3$ \\
\hline Northwest & Small & Williamson & 1 & 1 & 786.12 & 0 & 8.92 & 2.03 & $1.0-2.0$ \\
\hline Ben White & Small & Travis & 0 & 0 & 14.56 & 253 & 14.01 & 1.55 & $1.0-1.5$ \\
\hline
\end{tabular}


Table 11 (continued)

\begin{tabular}{lllrrrrrrr} 
Oak Hill & Small & Travis & 0 & 0 & 190.89 & 0 & 5.09 & 1.19 & $1.0-1.5$ \\
RM 2222 \& RM 620 & Small & Travis & 0 & 0 & 792.32 & 0 & 2.55 & 1.19 & $1.0-1.5$ \\
Taylor & Small & Williamson & 0 & 0 & 23.19 & 113 & 0.00 & 0.96 & $1.0-1.3$ \\
Lu ling & Small & Caldwell & 0 & 0 & 98.71 & 52 & 0.00 & 0.83 & $1.0-1.3$ \\
Jarrell & Small & Williamson & 0 & 0 & 581.99 & 0 & 0.00 & 0.71 & $1.0-1.3$ \\
Dripping Springs & Small & Hays & 0 & 0 & 1028.30 & 36 & 0.00 & 0.70 & $1.0-1.3$ \\
SH 130 \& SH 71 & Small & Travis & 0 & 0 & 1201.42 & 0 & 0.00 & 0.65 & $1.0-1.3$ \\
Mueller & Small & Travis & 0 & 0 & 48.63 & 0 & 5.09 & 0.59 & $1.0-1.3$ \\
Buda & Small & Hays & 0 & 0 & 137.05 & 273 & 0.00 & 0.56 & $1.0-1.3$ \\
Wimberley & Small & Hays & 0 & 0 & 238.56 & 0 & 0.00 & 0.55 & $1.0-1.3$ \\
Tech Ridge & Small & Travis & 0 & 1 & 122.38 & 0 & 12.73 & 0.43 & $1.0-1.5$ \\
Liberty Hill & Small & Williamson & 0 & 0 & 444.06 & 0 & 0.00 & 0.38 & $1.0-1.3$ \\
Manor & Small & Travis & 0 & 0 & 373.03 & 0 & 5.09 & 0.32 & $1.0-1.3$ \\
Smithville & Small & Bastrop & 0 & 0 & 176.83 & 0 & 0.00 & 0.32 & $1.0-1.3$ \\
South Austin Station & Small & Travis & 0 & 0 & 105.80 & 0 & 14.01 & 0.23 & $1.0-1.3$ \\
SH 130 \& US 290 & Small & Travis & 0 & 0 & 726.89 & 0 & 0.00 & 0.18 & $1.0-1.3$ \\
Mustang Ridge & Small & Travis & 0 & 0 & 505.39 & 0 & 0.00 & 0.12 & $1.0-1.3$ \\
Webberville & Small & Travis & 0 & 0 & 911.30 & 0 & 0.00 & 0.05 & $1.0-1.3$ \\
\hline
\end{tabular}




\section{DISCUSSIONS}

Although a rich literature review has testified supported commuting impact of jobs-housing balance, there are still conservative attitudes to jobs-housing balance as a policy tool to relieve traffic congestion and VMT (Giuliano1991, Peng 1997, Downs 2004). As Giuliano stated, jobs-housing ratio can be adopted for solving transportation problems in two contexts: jobs-housing balance can be only accomplished by government intervention; there is a significant impact of jobs-housing balance on travel patterns (Giuliano199, p. 305) Yang and Ferreira asked a more primary question: how can existing urban patterns be characterized with regard to spatial distribution of jobs and housing? (Yang \& Ferreira 2005, p. 171) How could jobs-housing balance ratio be a reliable and effective indicator for local municipalities? This section presents issues in the application of jobs-housing ratio and its effectiveness in guiding land use development.

Longitudinal evidence from many cities has revealed that jobs-housing balance is a dynamic process dominated by market force in urban development. First, the choice of location of residence and firms are the simultaneous process. Employers tent to locate firms close to labor pool and resident trend to buy houses near the workplaces. Second, commuting cost and personal preference and taste are taken into account with the choice of home location. Households tend to choose "utility-maximizing location" where extra commuting cost can be traded off with the marginal saving of housing and services. On 
the other hand, firms tend to locate close to their employees and customers. The colocation of employment and residence are adjusted over time. Thus, without government interventions, free market forces will push jobs-housing toward a general balance. Watterson's study also supports this view. He found that reduction in commuting duration is a strong factor that affects residential relocation and workplace changes. In the U.S., high mobility of residential locations and employment locations can adjust jobs-housing balance over time. Third, under the free market force, the correlation between jobs-housing balance and travel behavior is caused by residents' self-selection. For example, workers who prefer job accessibility to larger houses and more open spaces tend to reside close to the workplace and those who prioritize larger houses and good environment are willing to commute long distances. This self-selection process indicates that even if planning interventions achieved balanced jobs-housing ratio, there might be workers who move to imbalance neighborhoods (Peng 1997, p. 1231-1233).

The assumption that suburban residents will move to more balanced areas might be unrealistic unless extreme imbalance has caused high commuting. As a land use planning policy, the concept of jobs-housing balance ratio is built upon the hypothesis that the redistribution of employment and housing will change commuting patterns. This assumption is also built upon the homogeneity of preferences and tastes regarding commuting costs and housing location. In reality, workers who reside in suburban areas might not relocate their homes to downtown even if affordable housing is provided to 
improve jobs-housing balance because they have traded off the commuting cost with housing tastes (Giuliano 1991, Peng 1997).

Peng and Levine criticize the strategy of relocating employment to suburban areas to reduce commute time. Due to personal preferences and tastes, including school facilities, services, environment, and house size, suburban residents are motivated to move to exurb areas where their preferences could be satisfied, such as quiet environment and large land parcels. Jobs-housing balance achieved by planning interventions would be broken again by residents' self-selection (Peng 1997, Levine 1998). Hence, allocating firms in suburban areas might cause more urban sprawl and congestion in the long term. In addition, the relocation of employment in suburban workers pools might also increase transportation investment or reduce the availability of transit use. Therefore, if jobs-housing balance is used as a growth management tool, it is irrational and unfeasible to define an identical index throughout a broad metropolitan area.

Planners and policy makers should note that many factors can affect commuting patterns in addition to jobs-housing balance. Jobs-housing balance ratio just indicates a numerical balance and a potential for better balance. Although many studies show strong correlation between jobs-housing balance and commuting patterns, still many studies have proved weak relationship between travel pattern and jobs-housing balance (Downs 1992 \& 2004, Hamilton 1982, Miller \& Ibrahim 1998, Giuliano \& Small 1993). Peng's study also found population density and income greatly influence commute patterns. 
Many other factors play important roles in the selection process, including housing price, school quality, neighborhood characteristics, transportation availability, and environmental amenities (Peng 1997).

Notwithstanding this, the potential to achieve a better balance in jobs and housing exists in extreme imbalanced communities. Jobs-housing imbalance implies the failure of the market force in adjusting jobs and housing supply. Self-selection of home location or employment location are restricted or misguided by market force. Thus, the task of planning is to understand free market forces and eliminating obstacles to jobs-housing balance.

Improving jobs-housing balance, however, is not simply adjusting jobs-housing ratio. The numerical balance or imbalance might conceal the truth of commute patterns. For example, counties in the Central Texas show the numerical balanced job-employed resident ratios, but the percentage of long distance commuting have increased, and the self-containment have decreased between 2005 and 2010. This finding is consistent with Cervero and Giuliano's studies in larger metropolitan areas (Cervero 1989, Giuliano 1991). Cervero (1996) tracked the changes in jobs-housing ratios in the 20 largest cities in the San Francisco Bay Area in the 1980s, and the evidence shows that some cities have moved forward to a better balance, but frequent internal commuting trips generated an increasing VMT in total.

Thus, simply adding more jobs into the labor pool might decrease residence 
commuting distance but simultaneously increase commute time to workplaces. Thus, more detailed investigations should be accomplished. Demographic characteristics and socioeconomic characteristics as well as local cultural context should be highlighted when relocating jobs and housing in housing rich or job rich communities. In addition to housing price, housing type and associated amenities (school, clinic, commercial type) should meet the tastes and the needs of local workers. On the other hand, introducing job opportunities to housing rich communities should consider the match-up between job qualifications and residents' skills and education level. For example, beyond a numerical job-housing balance the Sacramento Area Council of Government conducted a "jobs-housing fit" investigation to achieve self-containment within 4 miles areas of regional employment centers.

Another dilemma of using jobs-housing ratio as a policy instrument is defining a good ratio of jobs-housing balance. Jobs-housing ratio is sensitive at different geographic scales. The ratio of jobs-employed residents at 1:1 is achievable at the metropolitan level but might not be a feasible goal for sub-regions. Determining the appropriate geographic units of jobs-housing ratio depends on local needs, the economic structure, and land use pattern of metropolitan areas. Primarily, planners should clarify the main purpose of defining jobs-housing ratio at different geographic scopes. Jobs-housing balance cannot be multiple solutions for metropolitan problems caused by urban sprawl or suburbanization, such as congestion, air pollution, and segregation (Giuliano 1991). 
Jobs-housing balance policy has been applied at the statewide, regional and local level (city/ county) with different planning goals. For example, the state of California Department of Finance set a statewide goal of 1.5 jobs per household based on 1.5 workers per household in California. Florida utilizes jobs-housing balance as an option to urban sprawl, while Oregon incorporates jobs-housing balance into transportation system planning to reduce car-dependence. Jobs-housing balance policy was adopted in administrative rules by Washington State and Georgia (Koh 2012).

While jobs-housing balance policy is applied at the regional level in the context of traffic mitigation and air pollution, the targeted ratios should be redefined in regional context, depending on region size, urban pattern, and the characteristics of commute pattern. For instance, with the goal of relieving interregional long distance commutes, the Southern California Association of Governments (SCAG) redefines a realistic targeted ratio range from 1.0 to 1.29 for cities in the Southern California region based on the analyses of commute time and demographic characteristics. Although six counties of SACOG have a relative balance of existing jobs-housing ratio, SACOG pursues a better balance at the sub-regional level. Within 4 miles of regional job centers, target jobs to household ratios were defined to move toward the regional ratio of 1.2 by 2035 . A “jobs-housing fit" measure at smaller geographic scale is also considered by SACOG to close the gap of worker income and housing cost in Southern California region (MTP/SCS 2035 Plan 2012, p. 3-38). 
When jobs-housing balance policy is applied at the local level, defining good jobs-housing ratio involves more specific consideration. For example, in Fairfax County, Washington D.C, which has an emphasis on providing housing in areas around transit stations and 13 regional activity centers, the target ratios of these centers were reduced based on average jobs-housing ratio by center type in the Metropolitan Washington area. Jobs-housing ratios for activity centers are distinctively higher than regional ratio and county/city ratio (Fairfax County Department of Planning \& Zoning 2012).

Whatever the geographic unit is defined, it is essential to note that the size of the metropolitan area and the degree of urbanization affects the usefulness of jobs-housing policy. Highly urbanized areas with high homogeneity of industrial clusters in a certain subarea, like the San Francisco Bay Area and Southern California, are more likely to generate large amount inter-regional work trips. In contrast, small communities tend to generate more internal work and non-work trips. Hence, for a small metropolitan region with rare cross-county work trip, it is meaningless to measure jobs-housing balance by county level. It is more practical to target balance at micro units, such as census tracts or TAZs, to reduce inner work trips. Empirical studies have shown that jobs-housing balance by commute shed comprised of aggregated TAZs or census tracts can largely reduce VMT (Frank 1994, Ferreira \&Yang 2002, Peng 1997), while counties with balanced ratios can hardly explain an increase in VMT (Cervero 1991\&1996, Giuliano 1989). Defining jobs-housing ratio by commute shed should consider the characteristics 
of travel patterns. A rational and reasonable commute shed should pay attention to commuters' acceptable travel distance. For example, Southern California initiated a survey to define jobs-housing balance areas within about 30-minute travel distance at an average speed of $28 \mathrm{mph}$ (Weitz 2003). Furthermore, acceptable travel distance differs in travel modes. For example, if jobs-housing balance policy attempts to encourage transit ridership in a given area around a transit station, it is helpful to set jobs-housing goal within an accessible transit service area. If multimode transportation means are considered, the catchment area may include areas within reasonable driving or biking distance to transit stations. In such a context, the definition of a good jobs-housing ratio should consider the capacity of land use and infrastructure and the economic incentives of measured area. In addition, the acceptable distance might be affected by other factors, such as culture and weather. For example, 15 minutes walking to a transit station might be common in northern cities, such as New York and Boston, but might be unacceptable in hot Texas.

When jobs-housing ratio is applied as land use policy, administrative limitations should be taken into account. For instance, in some states, counties have no legislative power over zoning, so it is useless to define jobs-housing balance by county rather than by city. In addition, a good jobs-housing ratio should meet the local needs.

Local municipalities should have knowledge of existing conditions about jobs-housing balance. The applicability of jobs-housing ratio strongly relies on 
communities' expectations. Some communities may prefer "semi-rural lifestyles" and keep bedroom status, while some may pursue non-residential development because of tax needs (Koh 2012, p. 30).

In conclusion, jobs-housing balance ratio is deceptive. Determining qualitative and quantitative balances between jobs and housing often requires a very specific dataset that cannot be obtained in most communities (Weitz 2003). Choosing a good ratio for a given area involves comprehensively understanding the relationship between jobs-housing ratio and urban pattern, commuting impact of existing urban pattern in local settings, future growth trend, as well as the impact of market force on jobs-housing proximity. Planners should keep in mind that improving jobs-housing balance is a dynamic process; however, this "extraordinarily difficult" (cited in Weitz 2003, p. 12) task could be accomplished through the following ways.

Table 11 Solutions to Improving Jobs-Housing Imbalance

\begin{tabular}{|l|l|}
\hline \multirow{4}{*}{ PERSPECTIVE } & \multicolumn{1}{|c|}{ APPROACHES } \\
\hline \multirow{4}{*}{$\begin{array}{l}\text { Planning and } \\
\text { Zoning }\end{array}$} & Setting Goals in Comprehensive Plan \\
& Adequate Land Development and Zoning Policy \\
\cline { 1 - 2 } & Mixed-Use Development \\
\hline \multirow{3}{*}{ Transportation } & Affordable Housing Program \\
& Density Bonuses, Incentives, and Flexibility in Land Development \\
\hline & Miles Traveled \\
\hline & Transit-Oriented Development \\
\hline & Transportation Demand Management Program \\
\hline
\end{tabular}


Table 11 (continued)

\begin{tabular}{|l|l|}
\hline & Transportation Infrastructure Improved/Expanded \\
\hline \multirow{3}{*}{ Public Policy } & Considering More than Only a Jobs-Housing Ratio \\
\cline { 2 - 2 } & Regional and Interregional Partnerships to Redirect Future Growth \\
\cline { 2 - 2 } & Statewide or Public Sector Tax and Incentive Programs \\
\hline & Jurisdictional and Regional Goals \\
\hline
\end{tabular}

Source: Jobs-Housing Ratios: National Perspective and Regional and Local

Benchmarks, Fairfax County Department Planning \& Zoning, Planning Division, 2012

http://www.fairfaxcounty.gov/dpz/

\section{CONCLUSIONS}

This report has explored the application and applicability of jobs-housing balance policy through a rich literature review of the definition of jobs-housing balance, ways to measure jobs-housing balance, and commuting impact of jobs-housing balance. The study aims to answer three core questions:

a. How should jobs-housing balance be applied as an effective policy in different local settings?

b. What is hidden beyond the definition of jobs-housing balance?

c. What is the appropriate way of defining good jobs-housing ratio in local context?

Based on empirical studies, this paper found that jobs-housing balance can only be used as transportation or land use policy when urban patterns are strongly shaped by 
the spatial distribution of jobs and housing and when a strong relationship between jobs-housing balance and travel patterns is found in local context. Otherwise, the performance of improving jobs-housing balance is hard to measure. As the initiative of improving jobs-housing balance is reducing congestion, it is crucial to examine the commuting impact of jobs-housing balance in a given area. Comprehensive investigations of existing conditions are the essential step for applying jobs-housing balance policy, such as existing land use patterns, commute patterns, demographic characteristics, socioeconomic characteristics, and the impact of market force on jobs-housing proximity.

Jobs-housing balance is measured by jobs-housing ratio or commuting. Jobs-housing ratio is the easiest way and widely used in many states. However, previous studies haven't demonstrated a consensus on good jobs-housing balance ratios. Recommended jobs-housing balance ratios vary in measurements and geographic units at local settings. Beyond numerical balance, jobs-housing balance are more influenced by other factors, such as match-up between jobs type and qualification of workers, worker's wage and housing price, market force, and self-selection including personal tastes, school facility, services, and environment.

Defining a good ratio of jobs and housing balance involves specific factors, depending on measured geographic units and planning goals. The appropriate geographic units of jobs-housing ratio are determined based on local needs, the economic structure and land use pattern of metropolitan areas. Jobs-housing balance policy has been applied 
at statewide, regional, local level (city/ county), and micro level (activity center, transportation corridor) with different planning goals. The size of metropolitan area and the degree of urbanization strongly affects the usefulness of jobs-housing policy because large communities and small communities usually have different land use patterns and travel patterns. As for small communities, the majority of previous studies have proved that defining jobs-housing balance ratio at micro level can largely reduce inner trips.

This study analyzed existing jobs-housing ratios in defined activity centers in Central Texas. Extreme mismatch exists between jobs and housing distribution based on estimated commute distance. However, existing jobs-household ratios can hardly explain this mismatch. Poor relationship was found between commute distance, self-containment, and jobs-household ratio. Activity centers with jobs-housing ratios ranging from 0.14 to 6.69 share the similar self-containment. The outcome of the case study, nevertheless, indicates the potential to improve jobs-housing balance through the adjustment of jobs-housing ratio.

A future extension of this study is to explore the impact of jobs-housing ratio on travel patterns. In order to define more appropriate measuring units related to acceptable commute shed, more detailed information about travel patterns will be considered, such as work and non-work VMT by activity center, out trips and inner trips for activity centers. An alternative way is conducting a survey for acceptable travel distance as commute shed. Beyond pursuing good jobs-housing ratio, future study should be aimed at 
promoting jobs-housing balance through improving the match-up between jobs and housing and more socioeconomic factors should be included. 


\section{References}

Bento, A. M., Cropper, M. L., Mobarak, A. M., \& Vinha, K. (2005). The effects of urban spatial structure on travel demand in the United States. Review of Economics and Statistics, 87(3), 466-478.

Bhat, C. R., Sivakumar, A., Sen, S., Guo, J., \& Copperman, R. (2004). Austin commuter survey: findings and recommendations. University of Texas at Austin.

Buliung, R.N., Kanaroglou, P.S., 2002. Commute minimization in the Greater Torontoarea: applying a modified excess commute. Journal of Transport Geography 10,177-186.

Black, J.A., Katakos, A., 1987. Optimisation methods and the classification of city structure: theory and empirical testing. Environment and Planning B 14, 93-107.

Capital Area Metropolitan Planning Organization (CAMPO). (2010, May). CAMPO 2035 regional transportation plan.

Capital Area Metropolitan Planning Organization. (2012,August). History and background of CAMPO 2035 centers concept. http://www.campotexas.org/pdfs/CentersHistoryandBackground.pdf

Capital Area Metropolitan Planning Organization. (2013, April).Revised CAMPO Centers Criteria

Capital Area Council of Governments. (n.d.). Commuting patterns. Retrieved June 31, 2013, from CAPCOG website:

http://www.capcog.org/data-maps-and-reports/central-texas-regional-data/\#comm utingpatterns

Capital Area Metropolitan Planning Organization. CAMPO 2035 Regional Transportation Plan. Austin, Tx: Capital Area Metropolitan Planning Organization, 2010. 
Capital Area Council of Governments. (2013, June 14). County boundaries [Geospatial data].Retrievedfrom http://www.capcog.org/data-maps-and-reports/geospatial-data/

Capital Area Metropolitan Planning Organization. (2013, June). 2005 to 2035 demographics [Geospatial data]. Retrieved from http://www.campotexas.org/programs_gis.php

California Planning Roundtable. Deconstructing Jobs-housing Balance. N.p.: California Planning Roundtable, 2008.

Cervero, R. (1989). Jobs-housing balancing and regional mobility. Journal of the American Planning Association, 55(2), 136-150.

Cervero, R. (1991). "Jobs Housing Balance as a public policy." Urban Land $50(10), 10-14$.

Cervero, R. (1996). Jobs-housing balance revisited: trends and impacts in the San Francisco Bay Area. Journal of the American Planning Association, 62(4), 492-511.

Cervero, R. (1995). Planned communities, self-containment and commuting: a cross-national perspective. Urban Studies, 32(7), 1135-1161.

Cervero, R., \& Duncan, M. (2006). 'Which Reduces Vehicle Travel More: Jobs-Housing Balance or Retail-Housing Mixing?. Journal of the American Planning Association, 72(4), 475-490.

Charron, M. (2007). From excess commuting to commuting possibilities: more extension to the concept of excess commuting. Environment and Planning A, 39(5), 1238.

City of Austin Planning and Development Review. (n.d.). Land use 2010 [Geospatial data]. Retrieved June 31, 2013, from COA website: ftp://ftp.ci.austin.tx.us/GIS-Data/Regional/coa_gis.html 
Downs, A. (1992). Stuck in Traffic: Coping with Peak-Hour Traffic Congestion. The Brookings Institution Press, Washington, DC.

Downs, A. (2004). Still stuck in traffic: Coping with peak-hour traffic congestion. The Brookings Institution Press, Washington, DC.

El-Geneidy, A. M., \& Levinson, D. M. (2006). Access to destinations: Development of accessibility measures (No. MN/RC-2006-16).

Ewing, R., \& Cervero, R. (2001). Travel and the built environment: a synthesis. Transportation Research Record: Journal of the Transportation Research Board, 1780(1), 87-114.

Ewing, R., M. DeAnna, et al. (1996). "Best development practices: Doing the right thing and making money at the same time " Urban Land Institute; Florida. Dept. of Community Affair.

Frank, L., Pivo, G. (1994) Relationships between Land Use and Travel Behavior in the Puget Sound Region. 397 Seattle: Washington State Transportation Center.

Frank, L. D. (1994). "An Analysis of relationships between urban form (Density, Mix and Jobs: Housing balance) and travel behavior (mode choice, trip generation, trip length and travel time)" Transportation Research Part A: Policy and Practice.

Giuliano, G. 1991. Is Jobs-Housing Balance a Transportation Issue? Transportation Research Record, no. 1305, pp. 305-312. San Francisco: The University of California Transportation Center

Giuliano, G., Small, K.A., 1993. Is the journey to work explained by urban structure? Urban Studies 30 (9), 1485-1500.

Giuliano, G. (1995). The weakening transportation-land use connection, 3-11.

Gordon, P., Richardson, H. W., \& Jun, M. J. (1991). The commuting paradox evidence from the top twenty. Journal of the American Planning Association, 57(4), 416-420.

Handy, S., Cao, X., \& Mokhtarian, P. L. (2006). Self-selection in the relationship between 
the built environment and walking: Empirical evidence from Northern California. Journal of the American Planning Association, 72(1), 55-74.

Hamilton, B. W., \& Röell, A. (1982). Wasteful commuting. The Journal of Political Economy, 1035-1053.

Hamilton, B. W. (1989). Wasteful commuting again. The journal of political economy, 97(6), 1497-1504.

Horner, M. W. (2008). Optimal 'Accessibility Landscapes? Development of a New Methodology for Simulating and Assessing Jobs-Housing Relationships in Urban Regions. Urban Studies, 45(8), 1583-1602.

Horner, M. W., \& Marion, B. M. (2009). A Spatial Dissimilarity-based Index of the Jobs_-Housing Balance: Conceptual Framework and Empirical Tests. Urban Studies, 46(3), 499-517.

Horner, M.W., 2002. Extensions to the concept of excess commuting. Environment and Planning A 34, 543-566.

Horner, M. W., \& Mefford, J. N. (2007). Investigating urban spatial mismatch using job-housing indicators to model home-work separation. Environment and Planning A, 39(6), 1420.

Home + Transportation cost \% Income. (n.d.) Retrieved June 15, 2013, from H+T Affordability Index website: http://htaindex.cnt.org/map/

Immergluck, D., 1998. Job proximity and the urban employment problem: Do suitable nearby jobs improve neighborhood employment rates? Urban Studies35 (1), 7-23.

INRIX Traffic Scorecard. (n.d.). Retrieved July 2, 2013, from Inrix website: http://scorecard.inrix.com/scorecard/

Jobs-Housing Balance (Atlanta Regional Commission, Comp.). (2002, October). Jobs-Housing Ratios: National Perspectives and Regional and Local Benchmarks (Fairfax County Department of Planning \& Zoning, Comp.). (2012, December). Koh, J. (2012, April). To What Extent Do Municipalities in Metro Vancouver Support A 
Jobs-Housing Balance? An Evaluation of Official Community Plans in Metro Vancouver.

Layman, C. C., \& Horner, M. W. (2010). Comparing Methods for Measuring Excess Commuting and Jobs-Housing Balance. Transportation Research Record: Journal of the Transportation Research Board, 2174(1), 110-117.

Levinson, D. M., \& Gillen, D. (1998). The full cost of intercity highway transportation. Transportation Research Part D: Transport and Environment, 3(4), 207-223.

Levinson, D. M. and A. Kumar (1994). "The rational locator: why travel times have remained stable." Journal of the American Planning Association 60(3): 319-332.

Levine, J. (1998). "Rethinking accessibility and jobs-housing balance." Journal of the American Planning Association 64(2): 133-149.

Loo, Bechy. (2011) Jobs-housing balance in an era of population decentralization: An analytical framework and a case study, Journal of Transport Geography 19 pp.552-562

Margolis, J. (1957). Municipal fiscal structure in a metropolitan region. The Journal of Political Economy, 65(3), 225-236.

Ma, K.R., Banister, D., 2006a. Excess commuting: a critical review. TransportReviews 26 (6), 749-767.

Ma, K., Banister, D., 2006b. Extended excess commuting: a measure of the jobs housing imbalance in Seoul. Urban Studies 43 (11), 2099-2113

Ma, K. R., \& Banister, D. (2007). Urban spatial change and excess commuting. Environment and Planning A, 39(3), 630.

Macek, N. M., Khattak, A. J., \& Quercia, R. G. (2001). What Is the Effect of Commute Time on Employment?: Analysis of Spatial Patterns in New York Metropolitan Area. Transportation Research Record: Journal of the Transportation Research Board, 1780(1), 43-52.

Miller, E. J., \& Ibrahim, A. (1998). Urban form and vehicular travel: some empirical 
findings. Transportation Research Record: Journal of the Transportation Research Board, 1617(1), 18-27.

Miller, J. S. (2010). Feasibility of using jobs/housing balance in Virginia statewide planning (No. FHWA/VTRC 11-R1).

Niedzielski, M. A. (2006). A spatially disaggregated approach to commuting efficiency. Urban Studies, 43(13), 2485-2502.

Peng, Z. R. (1997). The jobs-housing balance and urban commuting. Urban studies, 34(8), 1215-1235.

Raja, A. Z. (2012, December). Linking jobs-housing balance, land use mix and commute to work.

Rankings, B., \& Hutheesing, N. (2013, April 24). The top 12 American bloomtowns. Retrieved July 14, 2013, from Bloomberg website: http://www.bloomberg.com/money-gallery/2013-04-24/the-top-12-american-boo $\underline{\text { mtowns.html }}$

Sacramento Area Council of Government. (February 2012). Metropolitan Transportation Plan Sustainable Communities Strategy (MTP/SCS 2035). http://www.sacog.org/2035/draft-final-mtpscs/

SCAG (2001). "The New Economy and Job-Housing Balance in Southern California". Southern California Association of Governments: 19-20.

Scott, D. M., Kanaroglou, P. S., \& Anderson, W. P. (1997). Impacts of commuting efficiency on congestion and emissions: case of the Hamilton CMA, Canada. Transportation Research Part D: Transport and Environment, 2(4), 245-257.

Shen, Q. (2000). Spatial and social dimensions of commuting. Journal of the American Planning Association, 66(1), 68-82.

Sultana, S.(2002). "Job/housing imbalance and commuting time in the Atlanta metropolitan area: Exploration of causes of longer commuting time." Urban Geography 23(8): 728-749. 
Stoker, P., \& Ewing, R. (2013). JOB-WORKER AND INCOME BALANCE IN THE UNITED STATES. In Transportation Research Board 92nd Annual Meeting (No. 13-1522).

Stoker, P., \& Ewing, R. WORKFORCE HOUSING APP.

Transportation and Housing Costs. (n.d.). Retrieved July 1, 2013, from Livability Initiative website: http://www.fhwa.dot.gov/livability/fact_sheets/transhouse_attch1.cfm

Transportation and Housing Costs. (n.d.). Retrieved June 31, 2013, from Livability Initiative website: http://www.fhwa.dot.gov/livability/fact_sheets/transhouse_attch1.cfm

Transportation Costs. (n.d.). Retrieved June 30, 2013, from Smart Growth America website:

http://www.smartgrowthamerica.org/complete-streets/complete-streets-fundament $\underline{\text { als/factsheets/transportation-costs }}$

Transportation Research Board of National Academes. (2004). TCRP Report 102 (Research Report No. 2004107489) (R. Cervero, S. Murphy, \& C. Ferrell, Authors). Washington D.C., The United States.

Turner, M. A., Popkin, S. J., \& Rawlings, L. (2009). Public housing and the legacy of segregation. The Urban Insitute.

Wang, D., \& Chai, Y. (2009). The jobs-housing relationship and commuting in Beijing, China: the legacy of $<\mathrm{i}>$ Danwei</i $>$. Journal of Transport Geography, 17(1), $30-38$.

Wang, F. (2001). Explaining intraurban variations of commuting by job proximity and workers' characteristics. Environment and Planning B, 28(2), 169-182.

Weitz, J., A. P. Association, et al. (2003). "Jobs-housing balance." American Planning Association Chicago, IL. 
White, M.J., 1988. Urban commuting journeys are not "wasteful”. The Journal of Political Economy 96 (5), 1097-1110.

Yang, J., \& Ferreira, J. R. (2005). Evaluating measures of job-housing proximity: Boston and Atlanta, 1980-2000. Access to Destinations, 7, 171-192.

Yang, J., 2008. Policy implications of excess commuting: examining the impacts of changes in US metropolitan spatial structure. Urban Studies 45 (2), 391-405.

Zehner, R.B. (1977). Access, travel, and transportation in new communities. Ballinger Publishing Company, Cambridge, MA.

Zhang, M., Shen, Q., \& Sussman, J. (1999). Strategies to improve job accessibility: Case study of Tren urbano in San Juan metropolitan region. Transportation Research Record: Journal of the Transportation Research Board, 1669(1), 53-60.

Zhao, P., Lu, B., \& Linden, G. J. (2009). The Effects of Transport Accessibility and JobsHousing Balance on Commuting Time: Evidence from Beijing. International planning studies, 14(1), 65-83.

Zhou, J., Wang, Y., \& Schweitzer, L. (2012). Jobs/housing balance and employer-based travel demand management program returns to scale: Evidence from Los Angeles. Transport Policy, 20, 22-35.

http://onthemap.ces.census.gov/. (n.d.). Retrieved July 25, 2013, from Longitudinal Employer-Household Dynamics website: http://lehd.ces.census.gov/ http://www.ontarioplan.org/index.cfm/31581. (n.d.). Retrieved July 6, 2013, from The Ontario Plan website: http://www.ontarioplan.org/index.cfm/31581 Metro, Capital, M. (2013, June 15). Capital Metro MetroRail Red Line [Geospatial Data]. Retrieved from http://lcmtagis1 \gis\Download_Folderlcmta_metrorail.shp 